\title{
Integrated Optimization of Bus Line Fare and Operational Strategies Using Elastic Demand
}

\author{
Chunyan Tang, ${ }^{1}$ Avishai (Avi) Ceder, ${ }^{2,3}$ and Ying-En Ge ${ }^{4,5}$ \\ ${ }^{1}$ School of Transportation \& Logistics, Dalian University of Technology, 2 Linggong Road, Ganjingzi District, \\ Dalian, Liaoning 116024, China \\ ${ }^{2}$ Transportation Research Centre, Department of Civil and Environmental Engineering, 20 Symonds Street, \\ University of Auckland, Auckland, New Zealand \\ ${ }^{3}$ Faculty of Civil and Environmental Engineering, Technion-Israel Institute of Technology, 32000 Haifa, Israel \\ ${ }^{4}$ College of Transport \& Communications, Shanghai Maritime University, 1550 Haigang Avenue, Pudong, Shanghai 201306, China \\ ${ }^{5}$ School of Transportation \& Logistics, Faculty of Infrastructure Engineering, Dalian University of Technology, Dalian 116024, China
}

Correspondence should be addressed to Avishai (Avi) Ceder; a.ceder@auckland.ac.nz

Received 6 December 2016; Revised 11 March 2017; Accepted 30 March 2017; Published 20 April 2017

Academic Editor: S. C. Wong

Copyright (c) 2017 Chunyan Tang et al. This is an open access article distributed under the Creative Commons Attribution License, which permits unrestricted use, distribution, and reproduction in any medium, provided the original work is properly cited.

\begin{abstract}
An optimization approach for designing a transit service system is proposed. Its objective would be the maximization of total social welfare, by providing a profitable fare structure and tailoring operational strategies to passenger demand. These operational strategies include full route operation (FRO), limited stop, short turn, and a mix of the latter two strategies. The demand function is formulated to reflect the attributes of these strategies, in-vehicle crowding, and fare effects on demand variation. The fare is either a flat fare or a differential fare structure; the latter is based on trip distance and achieved service levels. This proposed methodology is applied to a case study of Dalian, China. The optimal results indicate that an optimal combination of operational strategies integrated with a differential fare structure results in the highest potential for increasing total social welfare, if the value of parameter $\varepsilon$ related to additional service fee is low. When this value increases up to more than a threshold, strategies with a flat fare show greater benefits. If this value increases beyond yet another threshold, the use of skipped stop strategies is not recommended.
\end{abstract}

\section{Introduction}

There has been a considerable increase in numbers for citizen travel, travel frequencies, and travel distances in the past few decades, which arose from the continuous increase in urban interspace and the development of city economies. Aside from the fact that the increased number of private cars could obviously not efficiently cover these increasing trips, they generate urban concerns such as traffic congestion and air pollution, as well as health and safety problems, and so on. Compared with the performances of private cars, public transit clearly can perform in an environmentally friendly, efficient, and sustainable manner $[1,2]$. However, in practice, full advantage is not always taken of public transit resources to meet such increasing and imbalanced travel demand, due to the fact that a common full route operation strategy is provided. Such an operation situation could be efficiently improved by the use of other strategies tailored to the greatest degree possible to meet observed passenger demand. This is because the use of strategies opens up an opportunity to further save on vehicles while ensuring that the passenger load on each route segment does not exceed the desired occupancy. Furthermore, by applying strategies, it is expected that not only will passenger travel times and crowding times in vehicles be significantly reduced, but bus operational emissions will even decrease, due to the reduction in the numbers of "stop" and "go" locations which will significantly contribute to air quality and environmental improvement.

Fundamentally, transit operational strategies include short turn, limited stop, deadheading, express, and zonal service all of which were initially illustrated by Furth and Day [3]. For instance, short turn strategy is useful when high passenger demand areas require attention; it can perform shorter round trip time and, thereby, increase service frequencies in 
specific areas along a bus line (e.g., city center or a residential area). Limited stop serves only a subset of stops on a route; thus stops with high demand are more frequently served than those stops with low demand. This strategy has also demonstrated that it can significantly improve transit system efficiency and better accommodate capabilities and needs with respect to supply and demand. Further studies are of Furth [4] and Ceder [5] who investigated the short turn strategy based on analyzing operational characteristics of full and partial route segments. These studies considered a given timetable and in Ceder [5] also the minimization of the number of vehicles required. Other studies of Delle Site and Filippi [6], Tirachini et al. [7], and Cortés et al. [8] dealt with the minimization of the total social cost for users and operators.

For limited stop strategy, based on the requirement of minimum level service, Fu et al. [9] formulated a model to design a dynamic stop-skipping strategy through minimizing total costs for users and operators. In their study, the headway allowed at any stop must not exceed double the dispatch headway. The study was extended by Liu et al. [10] and Chen et al. [11], considering random travel time and inserting deadheading strategy. Based on the same objective, Leiva et al. [12] allowed for two types of vehicles in the model for designing high frequency unscheduled limited stop strategy on a bus corridor. Considering running time variations resulting from the uncertainty of transit system operation, Tétreault and El-Geneidy [13] designed a limited stop strategy using archived automatic passenger counter and automatic vehicle location data. Meanwhile, based on these two types of data, El-Geneidy and Surprenant-Legault [14] evaluated the implementation of the limited stop strategy and demonstrated a saving in running time. Recently, a mixed integer nonlinear model, the objective of which was maximization of consumer surplus, was proposed by Chiraphadhanakul and Barnhart [15] for determining limited stop strategy on the basis of given bus trips.

Most of the studies investigated operational strategies with different objective functions; it shows that constructing operational strategies is beneficial to improve the efficiency of the public transit operations system. However, these studies ignore the possible impact on passenger demand. The change of the demand is, therefore, important to consider in the optimization formulation. The use of strategies is linked to service levels changes for two groups of passengers: (a) improved service for passengers whose origins and destinations are served though some of their intermediate stops is skipped and (b) reduced service for those passengers who want to board or alight at skipped stops. Therefore, naturally, potential passengers on segments with high service levels are likely to find use of public transit attractive. Alternatively, it is likely that passengers who have used public transit will discontinue this practice due to the low levels of service offered. As a result, there is a fluctuation in demand and its distribution induced by the use of strategies. Even though Ulusoy et al. [16] and Ulusoy and Chien [17] formulated an estimated demand function to determine the demand share for each strategy, such as all stop, short turn, and express strategies, according to their attributes, it was still based on the assumption of invariable demand. Thus, this paper considers variation of demand in the proposed method to obtain optimal topological characteristics of each strategy.

There are two common function forms used to describe variation of demand in the previous studies. The first form is exponential, presented in such studies as Evans [18], Yang and Huang [19], Lam and Zhou [20], Yang and Kin [21], and Bellei et al. [22], Yao et al. [23], Jørgensen et al. [24], and Klier and Haase [25]. Works on the other form, the linear function, have been done by Chang and Schonfeld [26], Chien and Spasovic [27], Tsai et al. [28], Savage [29], Li et al. [30], Chen et al. [11], and Kim and Schonfeld [31]. In these studies, two function forms have been proved to significantly reflect fluctuation of demand by changes in generalized costs of trips, though they are formulated in different expressions. Elements of generalized cost for a trip have been explored in modal choice [32-34], normally consisting of in-vehicle time, waiting time, access time, fare, comfort, and so on., but much work in public transport operations planning considered travel time and fare elements, ignoring crowding in vehicles. With improved level of life passengers are prone to increase the value of comfort items. For example, crowding in vehicles increases the value of time of passengers and hence their generalized travel cost [35]. In this paper, a linear demand function is developed to reflect the combined effects of attributes of strategies, crowding, and bus fare on demand.

Fare is found to be a key factor to capture in operational strategies planning context. There are four main elements related to fare: fare policy, strategies, structures, and enforcement technologies. An interaction among these four elements was illustrated in a report by Fleishman et al. [36]. The fare structure is the combination of one or more fare strategies with specific fare levels [36-39]. The different types of fare strategies are grouped into two basic categories: flat and differentiation. The flat one requires all passengers to pay the same fare, as studied by Evans [18], Chien and Spasovic [27], and Kim and Schonfeld [31]. When differential fare strategy is applied, passengers pay fare dependent on one or more factors, including length of trip, time of day, quality of service. Most studies on differential fare strategy, such as, Yang and Kin [21], Tsai et al. [28, 40], and Yook and Heaslip [41], concentrated on distance based factors.

The differences between flat fare and differential fare were discussed in detail by Fleishman et al. [36]. The flat fare was recognized as the simplest and most convenient, though it ignored equity. In contrast, the differentiated fare could display social equity while its implementation required the use of hi-tech collection systems, for example, smart bus or strip card, because an efficient way was needed to reduce the times by which passengers pay differently, often by a small amount. There is no doubt that adopting a differential fare in implementing public transit services presents a huge obstacle. However, as new technologies become less and less costly, they have gained applicability for use in collecting bus fare onboard. The problem has become how to develop an attractive and profitable fare structure.

These previous studies mainly focused on the optimization of FRO strategy with a flat or a differential fare structure 
using distance based methods. This paper, as indicated above, aims to examine effects of both fare types on operational strategy optimization, for three basic strategies, FRO, limited stop, and short turn, and a mix of limited stop and short turn strategies. A fare table is constructed which can serve to present either a flat fare or a differential fare structure, in accordance with fare policy objectives. Considering the attributes of operational strategies, the differential fare structure is constructed based on travel distance and obtained service levels. Finally, an optimal combination of fares and strategies is determined by optimizing total benefits consisting of consumer surplus and operator profit, considering the variation of demand.

Following this introductory section, Section 2 systematically describes system characteristics, constructs a fare table, and formulates optimization models. Section 3 presents an in-depth analysis of the results generated by applying the proposed models to a real life example of a single bus line. Conclusions and directions for future research are presented in Section 4.

\section{System Characteristics and Problem Formulation}

Considering a single and bidirectional bus line, stop locations, route zones, and greatest potential passenger demand along this bus line are given. The passenger demand is assumed to be sensitive to fare, waiting time, crowding time, and in-vehicle time. It is also assumed that passenger boarding and alighting have a significant effect on bus dwell times at stops. Thus, in-vehicle time depends on buses passing through the number of bus stops and passenger demand at these bus stops, as well as bus speed. Users are assumed to arrive randomly at stops. The distribution of bus arrivals at each stop presents Poisson distribution. We assume that passengers would not transfer between vehicles operated by different strategies on the single bus line because of high transferring cost considered. This study period is assumed to be a single period of one hour, such as the morning peak hour.

2.1. A Fare Structure Table. Fare is of considerable importance to bus operation and management. A low fare may attract more passengers but reduce operator revenue. Alternatively, a high fare may increase the revenue but reduce demand. Therefore, it is necessary to determine an attractive and profitable fare that benefits both users and operators. This paper defines a fare structure for a bus line, as shown in Table 1. This fare table consists of fares between each pair of all stops along a bus line, whether these two stops are successive or not. Suppose that there is a bus line with $n$ stops in each direction. A value of fare, $\mathrm{FA}^{i j}$, is defined for each pair $(i, j)$ of all stops along this bus line.

A Flat Fare Structure Table. In Table 1, values of a fare table for all $i \neq j$, are the same. This means that the bus operator charges all travelers a flat fare, regardless of travel distance, time of day, service quality, or trip route.
A Differential Fare Structure Table. In Table 1, the value of $\mathrm{FA}^{i j}$ completely or partly differs for each pair of stops $(i \neq j)$ along the bus line. If the value of $\mathrm{FA}^{i j}$ equals the value of $\mathrm{FA}^{j i}$, the resulting fare table is symmetrical.

The elements of a differential fare structure table vary in accord with differential fare strategies, such as distance based, time based, quality based, cost based, route based, and patron based strategies, as well as market based fare strategies. They depend on fare policy objectives. For instance, in order to attract more passengers to use public transit in off-peak periods, the transit service planner may consider varied discounts to lower fares during off-peaks, which could cause some users to shift their traveling times from peak to offpeak times. If the objectives of a fare policy are to increase the operator's revenue and achieve social equity, other differential fare strategies such as cost based, quality based, and distance based strategies are considered when setting bus fares. Accordingly, a differential fare structure table will display hundreds of thousands of possible bus fares for varied purposes of public transit service optimization. However, in consideration of transit system operation characteristics, this work constructs a differential fare structure based on travel distance and obtained service levels.

2.2. Notation. In order to formulate the methodology as a programming model, the parameters and variables are defined in Notation.

2.3. Demand Formulation. In this study, operational strategies are constructed based on passenger demand. Meanwhile, strategy application generates fluctuations in passenger demand because of the beneficial attributes of these strategies, like high speed between successive stops, greater comfort, and so on. Passenger demand on a single bus line is considered variations with respect to waiting time, in-vehicle time, fare, and in-vehicle crowding time, when designing strategies to further improve transit system efficiency.

(a) Waiting Time. The waiting time for an $O-D$ pair depends on obtained operational strategies and their associated frequencies. The waiting time $\mathrm{TW}^{i j}$ for pair $(i, j)$ can be expressed as follows:

$$
\mathrm{TW}^{i j}=\frac{\lambda}{\sum_{l \in L} \delta_{i}^{l} \delta_{j}^{l} f_{l}} .
$$

The product term between two binary variables, $\delta_{i}^{l} \delta_{j}^{l}$, in (1) equals 1 only if strategy $l$ serves stops $i$ and $j$, otherwise 0 .

(b) In-Vehicle Time. The in-vehicle time that a user experiences on a bus consists of running time and all dwell times at each intermediate stop visited by the bus. The total dwell time of strategy $l$ between stop $i$ and stop $j$ depends on passenger boarding and alighting times at each stop and a constant $\theta$ consisting of deceleration/acceleration as well as doors opening and closing at each stop. Passenger boarding and 
TABLE 1: A fare structure table for a bus line.

\begin{tabular}{|c|c|c|c|c|c|c|c|c|c|}
\hline \multirow{2}{*}{$O$} & \multicolumn{9}{|c|}{$D$} \\
\hline & 1 & 2 & $\ldots$ & $i$ & $\ldots$ & $j$ & $\ldots$ & $n-1$ & $n$ \\
\hline 1 & 0 & $\mathrm{FA}^{12}$ & $\ldots$ & $\mathrm{FA}^{1 i}$ & $\ldots$ & $\mathrm{FA}^{1 j}$ & $\ldots$ & $\mathrm{FA}^{1 n-1}$ & $\mathrm{FA}^{1 n}$ \\
\hline 2 & $\mathrm{FA}^{21}$ & 0 & $\ldots$ & $\mathrm{FA}^{2 i}$ & $\ldots$ & $\mathrm{FA}^{2 j}$ & $\ldots$ & $\mathrm{FA}^{2 n-1}$ & $\mathrm{FA}^{2 n}$ \\
\hline$\vdots$ & $\vdots$ & $\vdots$ & 0 & $\ldots$ & $\ldots$ & $\ldots$ & $\ldots$ & $\ldots$ & $\ldots$ \\
\hline$i$ & $\mathrm{FA}^{i 1}$ & $\mathrm{FA}^{i 2}$ & $\vdots$ & 0 & $\cdots$ & $\mathrm{FA}^{i j}$ & $\ldots$ & $\mathrm{FA}^{i n-1}$ & $\mathrm{FA}^{i n}$ \\
\hline$\vdots$ & $\vdots$ & $\vdots$ & $\vdots$ & $\vdots$ & 0 & $\cdots$ & $\cdots$ & $\ldots$ & $\cdots$ \\
\hline$j$ & $\mathrm{FA}^{j 1}$ & $\mathrm{FA}^{j 2}$ & $\vdots$ & $\mathrm{FA}^{j i}$ & $\vdots$ & 0 & $\ldots$ & $\mathrm{FA}^{j n-1}$ & $\mathrm{FA}^{\mathrm{jn}}$ \\
\hline$\vdots$ & $\vdots$ & $\vdots$ & $\vdots$ & $\vdots$ & $\vdots$ & $\vdots$ & 0 & $\ldots$ & $\ldots$ \\
\hline$n-1$ & $\mathrm{FA}^{n-11}$ & $\mathrm{FA}^{n-12}$ & $\vdots$ & $\mathrm{FA}^{n-1 i}$ & $\vdots$ & $\mathrm{FA}^{n-1, j}$ & $\vdots$ & 0 & $\mathrm{FA}^{n-1 n}$ \\
\hline$n$ & $\mathrm{FA}^{n 1}$ & $\mathrm{FA}^{n 2}$ & $\vdots$ & $\mathrm{FA}^{n i}$ & $\vdots$ & $\mathrm{FA}^{n j}$ & $\vdots$ & $\mathrm{FA}^{n n-1}$ & 0 \\
\hline
\end{tabular}

Note. $O, D$ represent passenger origin and destination, respectively.

alighting times of strategy $l$ at stop $p$, respectively, denoted as $\mathrm{BT}_{p}^{l}$ and $\mathrm{AT}_{p}^{l}$, are expressed as follows:

$$
\begin{aligned}
& \mathrm{BT}_{p}^{l}=\sum_{i \in N} \sum_{j \in N} \eta_{p}^{i j} \frac{V_{i j} \delta_{i}^{l} \delta_{j}^{l}}{\sum_{k \in L}\left(\delta_{i}^{k} \delta_{j}^{k}\right) f_{k}} t_{b} \\
& \mathrm{AT}_{p}^{l}=\sum_{i \in N} \sum_{j \in N} \gamma_{p}^{i j} \frac{V_{i j} \delta_{i}^{l} \delta_{j}^{l}}{\sum_{k \in L}\left(\delta_{i}^{k} \delta_{j}^{k}\right) f_{k}} t_{a} .
\end{aligned}
$$

In addition, it is also assumed in this paper that the processes of boarding and alighting are simultaneous (different doors for boarding and alighting) and that boarding and alighting flows are independent of each other. Therefore, the larger one between passenger boarding and alighting times at a stop is dwell time of strategy serving this stop. Accordingly, dwell time of strategy $l$ between stop $i$ and stop $j, \mathrm{DT}_{l}^{i j}$, is expressed as follows:

$$
\mathrm{DT}_{l}^{i j}=\sum_{p \in N_{l}} \phi_{p}^{i j}\left(\max \left\{\mathrm{BT}_{p}^{l}, \mathrm{AT}_{p}^{l}\right\}+\delta_{p}^{l} \theta\right) .
$$

Thus, the average in-vehicle time $\mathrm{TV}^{i j}$ for pair $(i, j)$ which also equals the average travel time of a bus from stop $i$ to stop $j$ is formulated as follows:

$$
\mathrm{TV}^{i j}=\frac{\sum_{l \in L} \delta_{i}^{l} \delta_{j}^{l}\left(\mathrm{RT}_{l}^{i j}+\mathrm{DT}_{l}^{i j}\right) f_{l}}{\sum_{k \in L} \delta_{i}^{k} \delta_{j}^{k} f_{k}} .
$$

\section{(c) Flat Fare and Differential Fare}

Flat Fare. Clearly, using a flat fare table indicates that all values of pairs are the same $U$, which is expressed as follows:

$$
\mathrm{FA}^{i j}=U
$$

Differential Fare. In this study, a differential fare structure table is determined based on trip distance and obtained service levels, though additional approaches are mentioned in Section 2.1. A pair $(i, j)$ with a long travel distance might consume more transit operation resources than a pair with a short travel distance. Subsequently, it is reasonable that a pair with a long distance trip should pay more for additional consumption of resources. In addition, feasible operational strategies are applied in this study, such as FRO, limited stop, short turn, and mixed strategies. Apparently, one of the important attributes characteristic of these strategies is that they provide different service levels for passengers. The greater the obtained service levels by pair $(i, j)$, the more it should pay. Therefore, passengers with the same travel distance may need to pay different fares due to their obtained different service levels. Weight factor of fare per unit distance for each pair is used to show this pair obtained service levels. In this study, service level or quality-of-service is measured by travel time savings, especially because of skipped stop strategies used. The number of skipped stops between stops $i$ and $j$ by strategy $l$ is calculated as follows:

$$
N_{l, \text { skip }}^{i j}=N^{i j}-\sum_{p \in N_{l}} \delta_{p}^{l}\left(\phi_{p}^{i j}+\eta_{p}^{i j}+\gamma_{p}^{i j}\right)
$$

The weight factor of fare per unit distance for pair $(i, j)$ on strategy $l, \pi_{l}^{i j}$, is expressed as follows:

$$
\pi_{l}^{i j}=1+\frac{N_{l, \text { skip }}^{i j}}{N^{i j}} .
$$

Thus, an integrated differential fare for pair $(i, j)$ based on trip distance and obtained service levels is the product of trip distance, unit fare, and the average associated weight factor. It is formulated as follows:

$$
\mathrm{FA}^{i j}=d^{i j} \operatorname{pr} \frac{\sum_{l \in L} \delta_{i}^{l} \delta_{j}^{l} f_{l} \pi_{l}^{i j}}{\sum_{k \in L} \delta_{i}^{k} \delta_{j}^{k} f_{k}} .
$$

(d) Crowding Time. The number of onboard passengers using strategy $l$ departing from stop $p, V S_{p}^{l}$, which consists of passengers boarding at stop $p$ and those passengers passing through stop $p$, is expressed as follows:

$$
V S_{p}^{l}=\sum_{i \in N} \sum_{j \in N} \phi_{p}^{i j} \frac{V_{i j} \delta_{i}^{l} \delta_{j}^{l}}{\sum_{k \in L}\left(\delta_{i}^{k} \delta_{j}^{k}\right) f_{k}}
$$




$$
+\sum_{i \in N} \sum_{j \in N} \eta_{p}^{i j} \frac{V_{i j} \delta_{i}^{l} \delta_{j}^{l}}{\sum_{k \in L}\left(\delta_{i}^{k} \delta_{j}^{k}\right) f_{k}} .
$$

When the number of onboard passengers $V S_{p}^{l}$ is beyond a threshold $A_{\max }$, it leads to crowding discomfort. The greater the rate between the number of onboard passengers and this threshold is, the more the crowding time for onboard passengers is [42]. Thus, the crowding time for pair $(i, j)$ using strategy $l, Y_{l}^{i j}$, is formulated as follows:

$$
Y_{l}^{i j}= \begin{cases}\sum_{p \in N_{l}}\left(\phi_{p}^{i j}+\eta_{p}^{i j}\right) \frac{V S_{p}^{l}}{A_{\max }} r t_{p} & V S_{p}^{l} \geq A_{\max } \\ 0 & V S_{p}^{l}<A_{\max } .\end{cases}
$$

Consequently, average crowding time for pair $(i, j), \mathrm{CR}^{i j}$, is formulated as follows:

$$
\mathrm{CR}^{i j}=\frac{\sum_{l \in L}\left(\delta_{i}^{l} \delta_{j}^{l} f_{l} Y_{l}^{i j}\right)}{\sum_{k \in L} \delta_{i}^{k} \delta_{j}^{k} f_{k}} .
$$

(e) Demand Function. The resulting number of passengers for pair $(i, j)$ along the bus line, $V_{i j}$, is formulated as

$$
\begin{aligned}
V_{i j} & =g_{i j}\left(1-e_{\mathrm{TW}} \mathrm{TW}^{i j}-e_{\mathrm{TV}} \mathrm{TV}^{i j}-e_{\mathrm{FA}} \mathrm{FA}^{i j}\right. \\
& \left.-e_{\mathrm{CR}} \mathrm{CR}^{i j}\right),
\end{aligned}
$$

where $e_{\mathrm{TW}}, e_{\mathrm{TV}}, e_{\mathrm{FA}}$, and $e_{\mathrm{CR}}$ are the sensitivity parameters for the waiting time, in-vehicle time, fare, and in-vehicle crowding time, respectively. It is noteworthy that these parameters are not the actual elasticities in this linear function. The ratios, $e_{\mathrm{TW}} / e_{\mathrm{FA}}, e_{\mathrm{TV}} / e_{\mathrm{FA}}$, and $e_{\mathrm{CR}} / e_{\mathrm{FA}}$, determine the value of waiting time, the value of in-vehicle time, and the value of crowding time, respectively $[11,26,30]$.

2.4. Fare and Operational Strategies Model with Elastic Demand. An efficient transit system matches the complex relationship between supply and demand from the users' and operators' perspectives $[1,2]$. Users pursue better service while the operator attempts to maximize operating profit. An attractive and efficient transit system will approach optimization of service from both perspectives.

(a) Consumer Surplus. Consumer surplus, $\mathrm{CS}_{\text {uers }}$, is the economic benefit to users. It is the price that users are willing to pay minus the price that they actually have to pay. Let $V_{i j}^{-1}(q)$ be the inverse function of elastic demand function for an $O-D$ pair $(i, j)$ as follows. $q$ is a demand variable with the upper boundary $V_{i j}$.

$$
\begin{aligned}
& V_{i j}^{-1}(q) \\
& \quad=\frac{1}{e_{\mathrm{FA}}}\left(1-e_{\mathrm{TW}} \mathrm{TW}^{i j}-e_{\mathrm{TV}} \mathrm{TV}^{i j}-e_{\mathrm{CR}} \mathrm{CR}^{i j}-\frac{q}{g_{i j}}\right) .
\end{aligned}
$$

Consumer surplus can be defined as follows [26, 43]:

$$
\mathrm{CS}_{\text {user }}=\sum_{i \in N} \sum_{j \in N} \int_{0}^{V_{i j}} V_{i j}^{-1}(q) \mathrm{d} q-\sum_{i \in N} \sum_{j \in N} V_{i j} \mathrm{FA}^{i j} .
$$

Substituting (13) into (14), the final consumer surplus is formulated as follows:

$$
\begin{aligned}
\mathrm{CS}_{\mathrm{user}} & =\sum_{i \in N} \sum_{j \in N} \frac{V_{i j}}{2 e_{\mathrm{FA}}}\left(1-e_{\mathrm{TW}} \mathrm{TW}^{i j}-e_{\mathrm{TV}} \mathrm{TV}^{i j}\right. \\
-e_{\mathrm{FA}} & \left.\mathrm{FA}^{i j}-e_{\mathrm{CR}} \mathrm{CR}^{i j}\right)^{2} .
\end{aligned}
$$

(b) Operator Profit. Operator profit consists of operator revenue minus operator cost. The operator cost, $C_{\text {operator }}$, equals the fleet size (bus round trip time multiplied by the frequency) multiplied by the hourly operating cost per bus. It is expressed as follows:

$$
\begin{aligned}
& C_{\text {operator }}=\sum_{l \in L}\left(\mathrm{RT}_{l}+K \mathrm{~T}_{l}\right. \\
& \left.\quad+\sum_{p \in N_{l}}\left(\max \left\{\mathrm{BT}_{p}^{l}, \mathrm{AT}_{p}^{l}\right\}+\delta_{p}^{l} \theta\right)\right) f_{l} \mathrm{CO}_{\text {operator }} .
\end{aligned}
$$

Operator revenue is considered only from passenger fares:

$$
G_{\text {operator }}=\sum_{i \in N} \sum_{j \in N} V_{i j} \mathrm{FA}^{i j} .
$$

Thus, operator profit function is formulated as

$$
\begin{gathered}
\mathrm{OP}_{\text {operator }}=\sum_{i \in N} \sum_{j \in N} V_{i j} \mathrm{FA}^{i j}-\sum_{l \in L}\left(\mathrm{RT}_{l}+K T_{l}\right. \\
\left.+\sum_{p \in N_{l}}\left(\max \left\{\mathrm{BT}_{p}^{l}, \mathrm{AT}_{p}^{l}\right\}+\delta_{p}^{l} \theta\right)\right) f_{l} \mathrm{CO}_{\text {operator }}
\end{gathered}
$$

(c) Model Formulation. The objective function considered is to maximize the sum of consumer surplus and operator profit. Thus, the operational strategies problem using elastic demand is formulated as follows:

Maximize $Z$

$$
=\sum_{i \in N} \sum_{j \in N} \frac{V_{i j}}{2 e_{\mathrm{FA}}}\left(1-e_{\mathrm{TW}} \mathrm{TW}^{i j}-e_{\mathrm{TV}} \mathrm{TV}^{i j}-e_{\mathrm{FA}} \mathrm{FA}^{i j}-e_{\mathrm{CR}} \mathrm{CR}^{i j}\right)^{2}+\sum_{i \in N} \sum_{j \in N} V_{i j} \mathrm{FA}^{i j}
$$




$$
-\sum_{l \in L}\left(\mathrm{RT}_{l}+K T_{l}+\sum_{p \in N_{l}}\left(\max \left\{\mathrm{BT}_{p}^{l}, \mathrm{AT}_{p}^{l}\right\}+\delta_{p}^{l} \theta\right)\right) f_{l} \mathrm{CO}_{\text {operator }}
$$

Subject to $\quad 0 \leq f_{l} \quad \forall l \in L$

$V S_{p}^{l} \leq Q \quad \forall p \in N_{l}, \forall l \in L$

$\delta_{p}^{l} \in\{0,1\} \quad \forall p \in N_{l}, \forall l \in L$

$\delta_{p}^{l}=1 \quad$ if $l=\mathrm{FRO}, \mathrm{ST}, \forall p \in N_{l}$

$\delta_{p}^{l}=1 \quad$ if $\forall p \in S$ or $\forall p \in E, \forall l \in L$

$\delta_{p}^{l}+\delta_{p+1}^{l}+\delta_{p+2}^{l} \geq 1 \quad$ if $l=$ LS, MLS, $\forall p \in\left\{1, \ldots, n_{l}-2\right\}$

$1-e_{\mathrm{TW}} \mathrm{TW}^{i j}-e_{\mathrm{TV}} \mathrm{TV}^{i j}-e_{\mathrm{FA}} \mathrm{FA}^{i j}-e_{\mathrm{CR}} \mathrm{CR}^{i j} \geq 0 \quad i, j \in N$

In this formulation, Constraint (20) guarantees that frequencies of strategies are nonnegative. Constraint (21) maintains that the number of onboard passengers departing from each stop is less than vehicle capacity. Constraint (22) shows whether or not strategies serve stops; it equals 1 if strategies serve stops and 0 otherwise. Constraint (23) ensures that all stops, including start and end stops of strategies and intermediate stops, can be visited by FRO and ST strategies. Constraint (24) makes sure that all strategies must visit their start and end stops. Constraint (25) guarantees that strategies involved with skipping stops do not skip more than three successive stops. Constraint (26) ensures that the expected demand for each pair is nonnegative and less than given potential demand.

The above problem is formulated as a mixed integer nonlinear programming (MINLP) problem. It can be handled by the outer approximation with both equality relaxation and augmented penalty (OA/ER/AP) algorithm of Viswanathan and Grossmann [44]. This algorithm starts by relaxing the integer requirement of decision variables and solving the relaxed nonlinear programming (NLP) problem. If an integer solution is not found, a sequence of iterations is solved consisting of NLP subproblems through fixing the integer variables and mixed integer linear program (MIP) master problems generated by augmented penalty function. This algorithm is readily available in the DICOPT solver of GAMS $[45,46]$. Conopt and Cplex are adopted to solve the DICOPT subproblems of NLP and MIP.

\section{Case Study}

In this section, a real bus line in the city of Dalian, China, Line 26 , is taken as a numerical example for applying the proposed models. Line 26, as shown in Figure 1 runs from Lingshui Passenger Transport Station to Wuyi Square, visiting 19 stops with $10.9 \mathrm{~km}$ in each direction, passing through a school zone (Dalian University of Technology, and the primary and high schools attached to Dalian University of Technology), a shopping center (Xian Road), and a business office zone (Software Park Service Center).

3.1. Data and Parameter Settings. In this case, a survey was conducted to collect route and travel demand data of Line 26 in the morning peak hour. The running time and distance between successive stops are shown in Table 2. Based on these collected demand data, the potential passenger demand $O$ $D$ matrix, for Line 26 in Table 3, was estimated. Accordingly, load profiles are also constructed, as shown in Figure 2.

Boarding time and alighting time per passenger are, respectively, $t_{a}=2 \mathrm{~s}$ and $t_{b}=1 \mathrm{~s}$. The value of a parameter consisting of acceleration/deceleration as well as door opening and closing times at each stop is $\theta=1 \mathrm{~min}$. The layover time of a strategy at turning point is $K T_{l}=2 \mathrm{~min}$. The demand elasticity parameters for wait time, in-vehicle time, and fare are $e_{\mathrm{TW}}=0.98, e_{\mathrm{TV}}=0.49, e_{\mathrm{FA}}=0.098$, and $e_{\mathrm{CR}}=0.049$, respectively $[11,30]$. The vehicle operating cost is $\mathrm{CO}_{\text {operator }}=\$ 80 /$ vehicle-hour. Capacity of a vehicle with 40 seats is $Q=85$ passengers. The maximum acceptable number of passengers inside vehicle is $A_{\max }=60$ passengers which generally is 125 to $150 \%$ of a bus's seating capacity. Typically loads above $150 \%$ of a bus's seating capacity subject standees and other passengers to unreasonable discomfort [47].

Figure 2 presents passenger load profiles for bus Line 26 in Dalian. The max-load segment of Line 26 is between stops 14 and 15 of direction 1 and between stops 15 and 16 the other direction; it is because both route segments are located in a building material market and the second biggest central business district (Xi'an Road), respectively. Based on the characteristics shown in Figure 2 it is possible to establish the sets of start and end stops of feasible operational strategies as is shown in Table 4.

3.2. Results. The optimal results obtained by the proposed methodology are shown in Table 5, taking a differential fare structure into account. It is evident that the optimal 


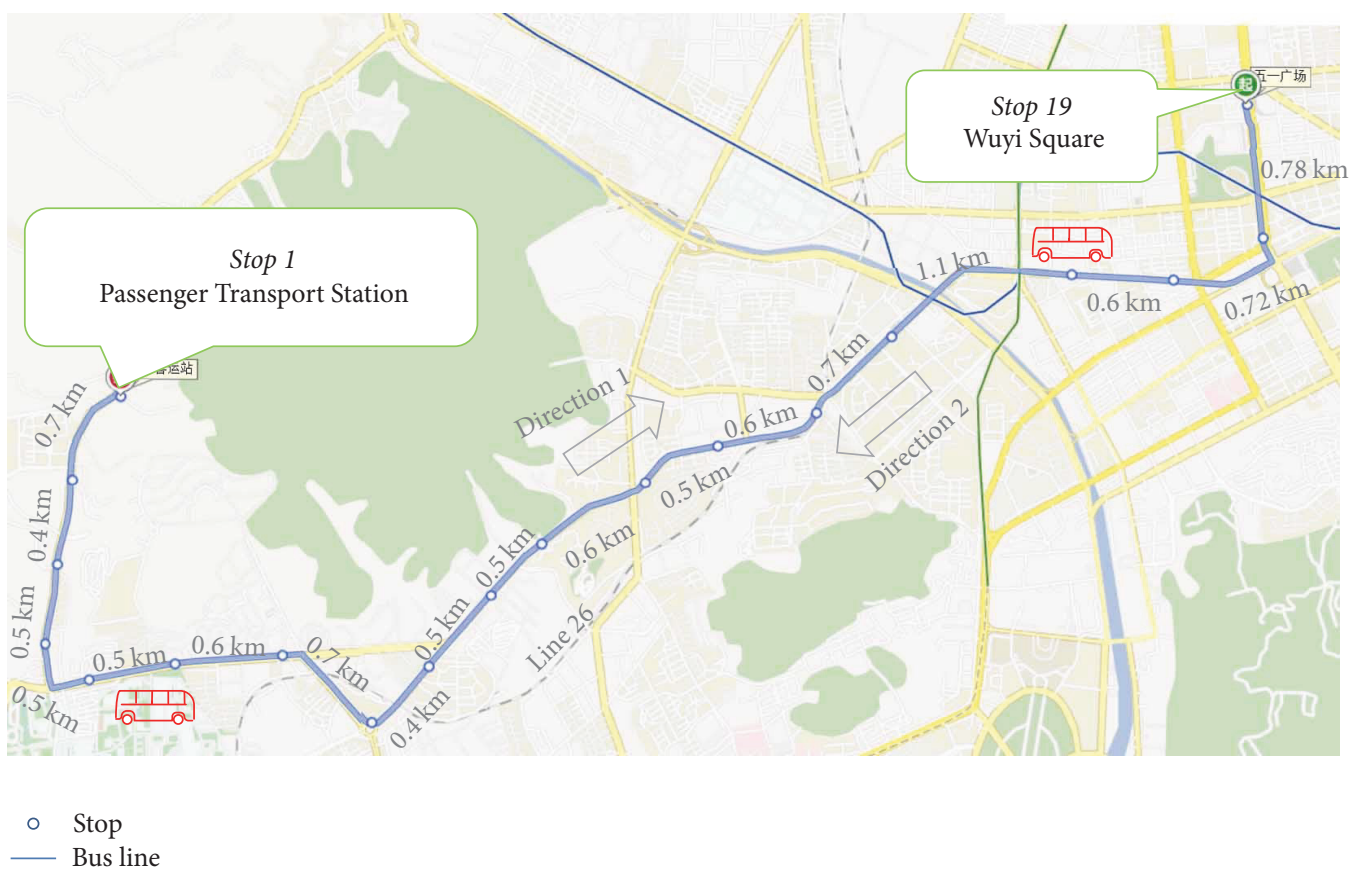

FIGURE 1: A real life transit route, Line 26, in Dalian.

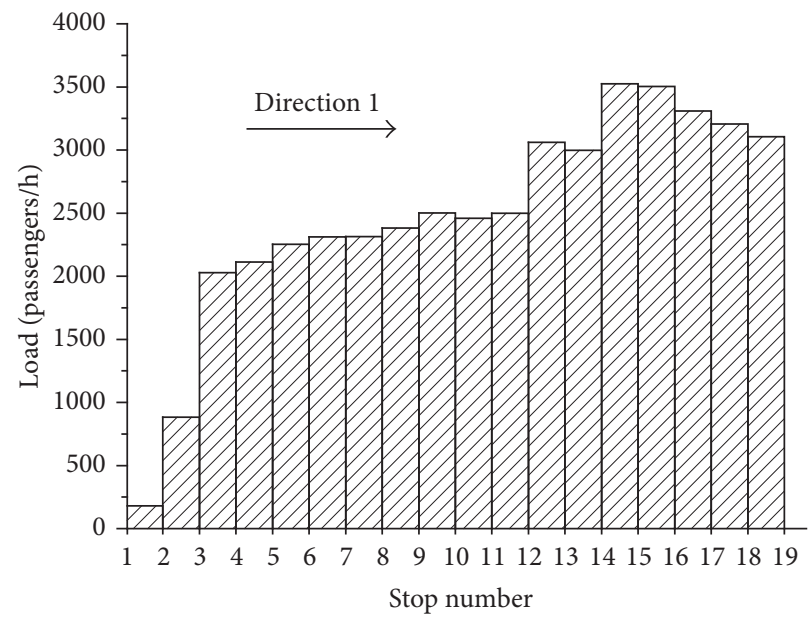

VIJ Passenger load

(a) Passenger load profile in Direction 1

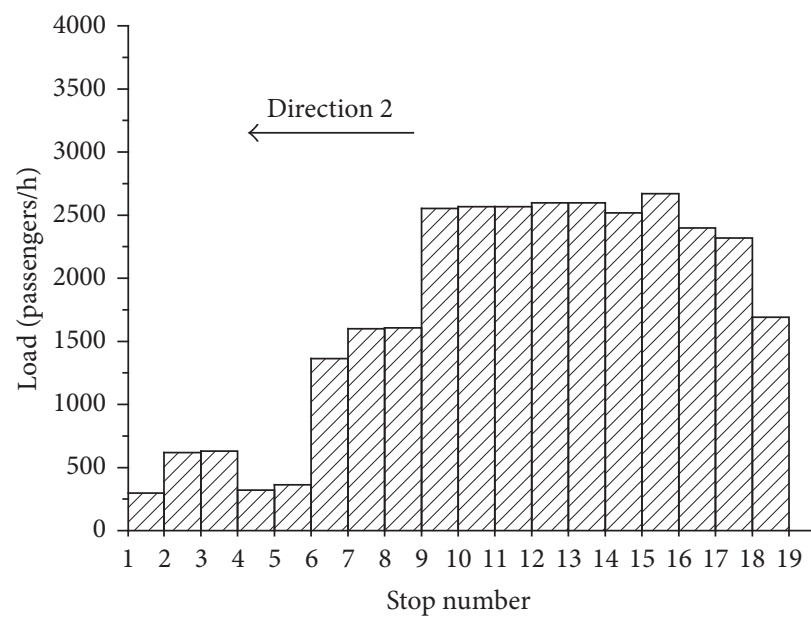

Z7] Passenger load

(b) Passenger load profile in Direction 2

FIgURE 2: Passenger load profiles on bus Line 26.

TABLE 2: Running time and distance between successive stops.

\begin{tabular}{lccccccccc}
\hline Segment & $1-2$ & $2-3$ & $3-4$ & $4-5$ & $5-6$ & $6-7$ & $7-8$ & $8-9$ & $9-10$ \\
\hline Running time (min) & 2 & 1.5 & 0.5 & 1.5 & 0.5 & 1.5 & 2.5 & 2 & 2 \\
Distance $(\mathrm{km})$ & 0.7 & 0.4 & 0.5 & 0.5 & 0.5 & 0.6 & 0.7 & 0.4 & 0.5 \\
\hline Segment & $10-11$ & $11-12$ & $12-13$ & $13-14$ & $14-15$ & $15-16$ & $16-17$ & $17-18$ & $18-19$ \\
\hline Running time (min) & 5.5 & 1.5 & 1.5 & 3.0 & 5.5 & 3.0 & 3.0 & 3.0 & 3.0 \\
Distance $(\mathrm{km})$ & 0.5 & 0.6 & 0.5 & 0.6 & 0.7 & 1.1 & 0.6 & 0.72 & 0.78 \\
\hline
\end{tabular}




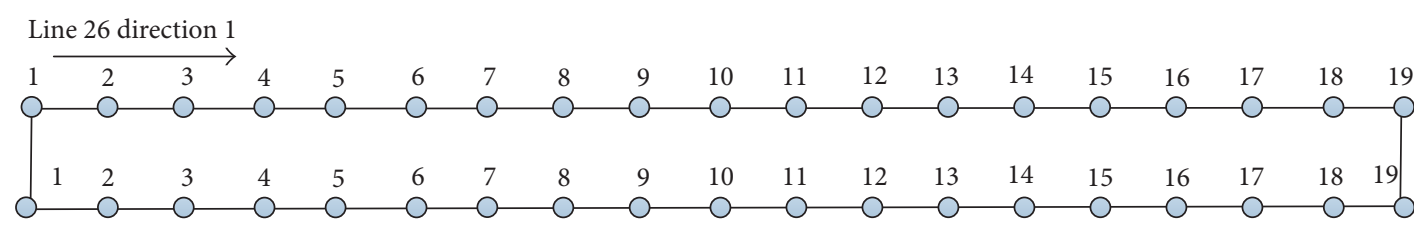

Line 26 direction 2

Stopping

(a) FRO strategy

Line 26 direction 1

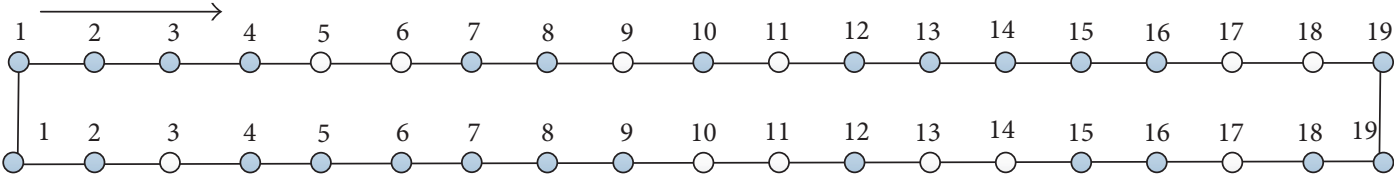

Line 26 direction 2

Stopping

O Skipping

(b) Limited strategy

FIGURE 3: Resulting strategies' topologies under scenario using optimal strategies.

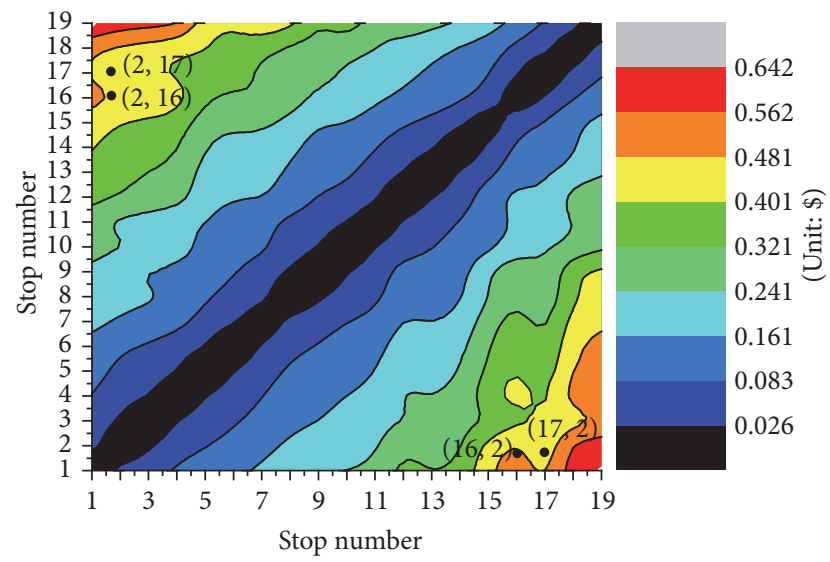

(a) Optimal fare for each pair with strategies

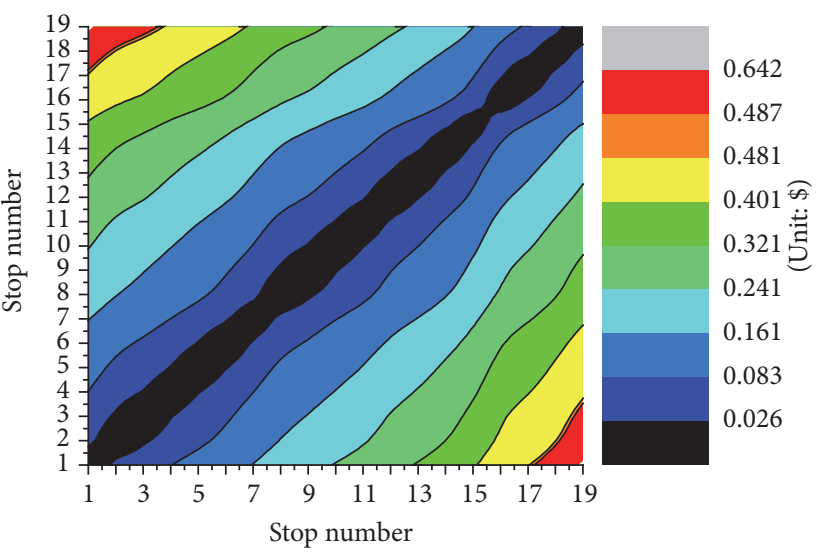

(b) Optimal fare for each pair with FRO strategy and no other strategies added

FIGURE 4: Optimal fares for each pair along a bidirectional bus line with and without use of strategies.

result is to operate a combination of all two strategies, FRO, limited stop, simultaneously with frequencies of 13.0 buses $/ \mathrm{h}$ and $14.8 \mathrm{bus} / \mathrm{h}$, respectively. Topological characteristics of these two resulting strategies are shown in Figure 3. The value of between two successive stops is in Figure 3. This optimal result is compared with the FRO strategy, without adding other strategies, to illustrate gains of $\$ 648.2 / \mathrm{h}$ for objective function value and consumer surplus of $\$ 771.8 / \mathrm{h}$ and attracting more than 124 passengers, despite a small decrease in operator profit of $\$ 123.6 / \mathrm{h}$. However, increased objective function value indicates that a gain in consumer surplus compensates for this decreased operator profit. This promising result indicates that optimal strategies for single line bus operation can be applied to real life public transit systems, to attract more passengers, and to increase consumer surplus and total gains.

In Section 2, a fare structure table is defined. In order to clearly illustrate optimal fare changes along a bus line, this fare table is converted to a visual figure, as shown in Figure 4 . The area in the upper triangle represents optimal fare for each pair in direction 1 of bus Line 26. Accordingly, the area in the lower triangle relates to optimal fares in the other direction. The pairs close to the diagonal have short travel distances, while those pairs far from the diagonal represent long distances. The optimal differential fare for each pair, with and without consideration for strategies, is presented in Figures 4(a) and 4(b), respectively. The optimal differential fare structure shown in Figure 4(b) is symmetrical 
TABLE 3: Potential passenger $O-D$ matrix for Line 26 (passengers/h).

\begin{tabular}{|c|c|c|c|c|c|c|c|c|c|c|c|c|c|c|c|c|c|c|c|}
\hline \multirow{2}{*}{$O$} & \multicolumn{19}{|c|}{$D$} \\
\hline & 1 & 2 & 3 & 4 & 5 & 6 & 7 & 8 & 9 & 10 & 11 & 12 & 13 & 14 & 15 & 16 & 17 & 18 & 19 \\
\hline 1 & 0 & 20 & 7 & 3 & 6 & 11 & 15 & 23 & 2 & 7 & 0 & 6 & 12 & 7 & 5 & 9 & 5 & 5 & 37 \\
\hline 2 & 8 & 0 & 13 & 7 & 12 & 25 & 30 & 45 & 3 & 14 & 0 & 13 & 24 & 13 & 10 & 19 & 9 & 9 & 474 \\
\hline 3 & 3 & 4 & 0 & 10 & 18 & 39 & 48 & 272 & 5 & 22 & 0 & 20 & 37 & 21 & 15 & 29 & 14 & 14 & 616 \\
\hline 4 & 222 & 233 & 5 & 0 & 4 & 9 & 10 & 15 & 1 & 5 & 0 & 4 & 8 & 4 & 3 & 6 & 3 & 3 & 25 \\
\hline 5 & 16 & 25 & 5 & 34 & 0 & 16 & 19 & 28 & 2 & 9 & 0 & 8 & 50 & 8 & 6 & 12 & 6 & 5 & 46 \\
\hline 6 & 6 & 8 & 1 & 12 & 13 & 0 & 18 & 29 & 2 & 9 & 0 & 8 & 14 & 8 & 6 & 11 & 5 & 5 & 45 \\
\hline 7 & 2 & 3 & 0 & 4 & 5 & 26 & 0 & 28 & 2 & 8 & 0 & 8 & 14 & 8 & 6 & 11 & 5 & 5 & 45 \\
\hline 8 & 10 & 15 & 2 & 21 & 24 & 325 & 43 & 0 & 3 & 15 & 0 & 214 & 126 & 14 & 11 & 20 & 10 & 9 & 78 \\
\hline 9 & 1 & 1 & 0 & 1 & 1 & 9 & 2 & 5 & 0 & 11 & 0 & 10 & 17 & 10 & 8 & 14 & 7 & 7 & 56 \\
\hline 10 & 0 & 0 & 0 & 0 & 0 & 1 & 1 & 1 & 2 & 0 & 0 & 5 & 8 & 5 & 4 & 7 & 3 & 3 & 25 \\
\hline 11 & 0 & 1 & 0 & 1 & 1 & 4 & 1 & 4 & 8 & 0 & 0 & 4 & 6 & 3 & 2 & 4 & 2 & 2 & 17 \\
\hline 12 & 0 & 0 & 0 & 0 & 0 & 3 & 1 & 2 & 4 & 0 & 0 & 0 & 39 & 22 & 17 & 31 & 15 & 15 & 721 \\
\hline 13 & 0 & 1 & 0 & 1 & 1 & 3 & 1 & 4 & 8 & 0 & 0 & 1 & 0 & 17 & 12 & 22 & 11 & 11 & 187 \\
\hline 14 & 1 & 3 & 0 & 4 & 4 & 21 & 7 & 18 & 37 & 1 & 1 & 2 & 1 & 0 & 15 & 28 & 13 & 13 & 611 \\
\hline 15 & 1 & 2 & 0 & 2 & 2 & 12 & 4 & 11 & 21 & 1 & 1 & 1 & 1 & 1 & 0 & 50 & 8 & 8 & 67 \\
\hline 16 & 3 & 5 & 1 & 7 & 8 & 38 & 13 & 33 & 167 & 2 & 2 & 4 & 2 & 2 & 13 & 0 & 4 & 4 & 32 \\
\hline 17 & 2 & 2 & 0 & 3 & 4 & 19 & 7 & 17 & 33 & 1 & 1 & 2 & 1 & 1 & 6 & 1 & 0 & 2 & 18 \\
\hline 18 & 6 & 9 & 1 & 12 & 13 & 168 & 23 & 59 & 317 & 3 & 3 & 7 & 3 & 4 & 23 & 4 & 4 & 0 & 20 \\
\hline 19 & 19 & 28 & 5 & 38 & 44 & 421 & 177 & 296 & 383 & 12 & 12 & 23 & 12 & 12 & 178 & 15 & 15 & 10 & 0 \\
\hline
\end{tabular}

TABLE 4: Start stops and end stops of feasible strategies.

\begin{tabular}{lcccc}
\hline \multirow{2}{*}{ Strategies } & \multicolumn{2}{c}{ Direction 1 } & \multicolumn{2}{c}{ Direction 2 } \\
& Start stop & End stop & Start stop & End stop \\
\hline FRO & Stop 1 & Stop 19 & Stop 19 & Stop 1 \\
Limited stop & Stop 1 & Stop 19 & Stop 19 & Stop 1 \\
Short turn & Stop 3 & Stop 19 & Stop 19 & Stop 9 \\
Mixed strategy & Stop 3 & Stop 19 & Stop 19 & Stop 9 \\
\hline
\end{tabular}

and represents increasing values of fares from the diagonal toward two sides, while, in Figure 4(a), it is nonsymmetric and not always increasing. This results from the fact that the optimal fare for each pair is determined on the basis of bus service levels provided for this pair and its travel distance, in this study. In Figure 4(b), only FRO strategy is provided along a bus line. This implies that the same bus service level is offered for all pairs in both directions. Therefore, the optimal fares in this transit operation system are attained based on trip distances. That is, pairs $(i, j)$ and $(j, i)$ present the same fare due to the same trip distance, and the longer the travel distance for a pair, the higher the fare should be. However, in Figure 4(a), optimal strategies are applied in the transit operation system, which provide different service levels for pairs. According to Figure 4(a), some of the pairs which have achieved high service levels can be identified. For instance, the fare for pair $(2,16)$ is higher than that for pair $(2,17)$ in Figure 4(a), though its travel distance is shorter than for pair $(2,17)$. This is adequate explanation that pair $(2,16)$ needs to be offered a high service level.

Interestingly, Figure 5 indicates that $O-D$ pairs located in those areas with difference values between their two fares

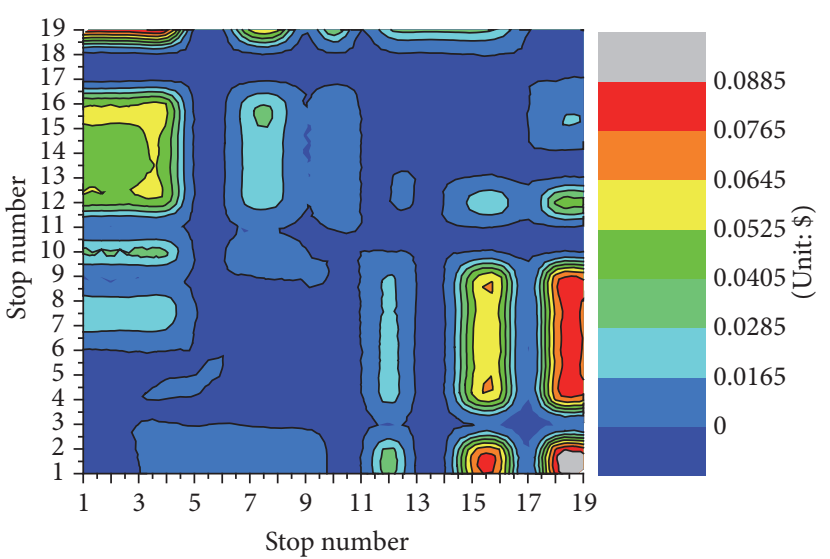

FIGURE 5: Optimal fares using strategies minus optimal fares without strategies.

beyond $\$ 0$ must be offered high quality service in the transit system which considers the use of strategies. Since compared with the unit fare from the model without consideration for strategies, the unit fare from the model considering these strategies is lower, as shown in Table 4 . When pairs from the latter pay more than that from the former, it indicates that these pairs must gain better service than from the former.

Figure 6 compares the optimal results from two models with a flat fare and a differential fare structure, respectively. It is found that using a differential fare structure produces greater benefits for passengers and society, though there is a slight decrease in the profit for operators (see Figure 6(e)). These benefits are performed in terms of gains of about $\$ 326.9 / \mathrm{h}$ for objective function value, an increase 


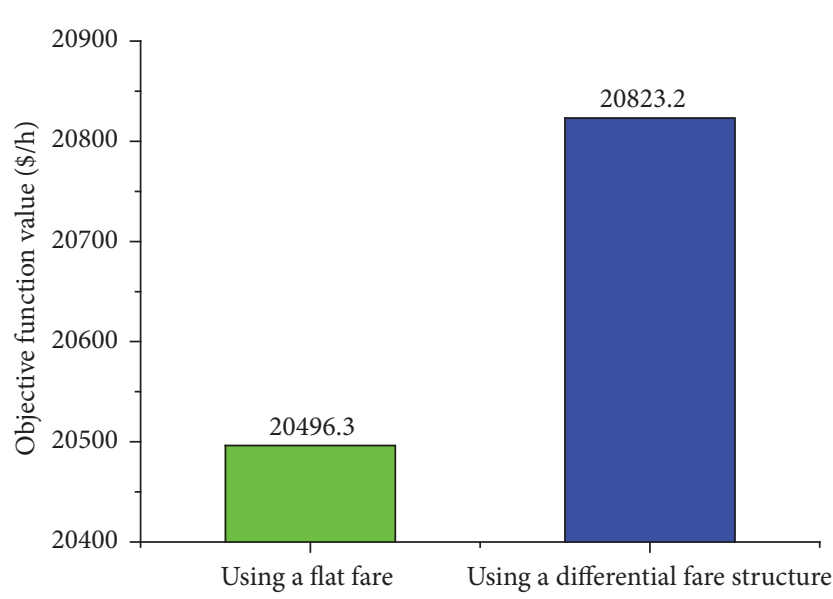

(a) Objective function values $(\$ / \mathrm{h})$

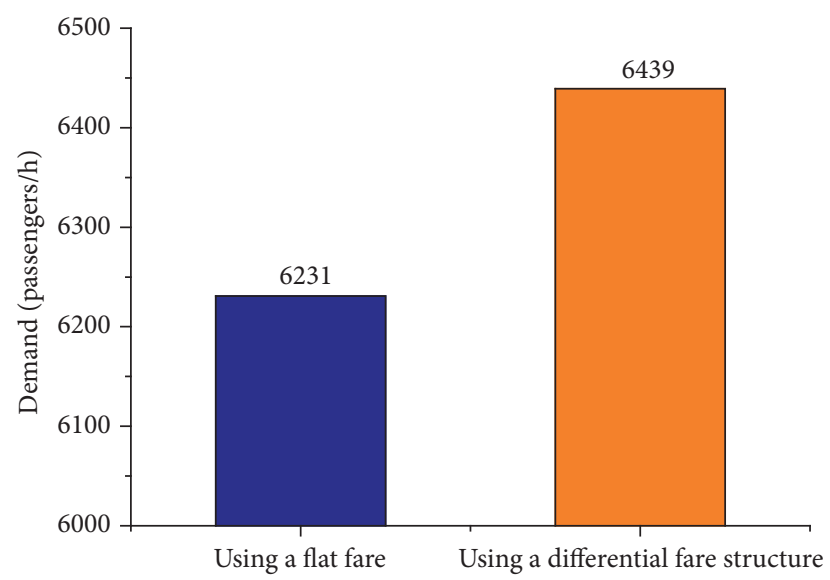

(c) Demands (passengers/h)

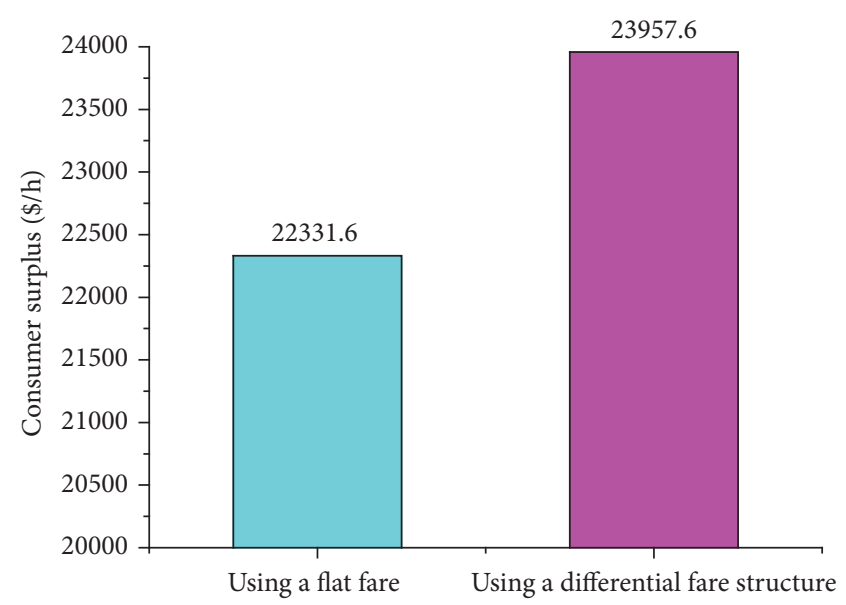

(b) Consumer surpluses $(\$ / \mathrm{h})$

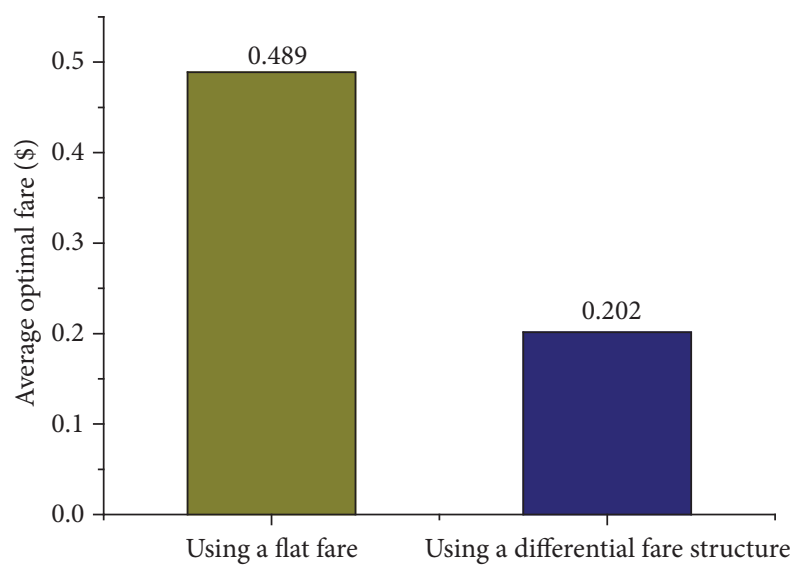

(d) Average optimal fares $(\$)$

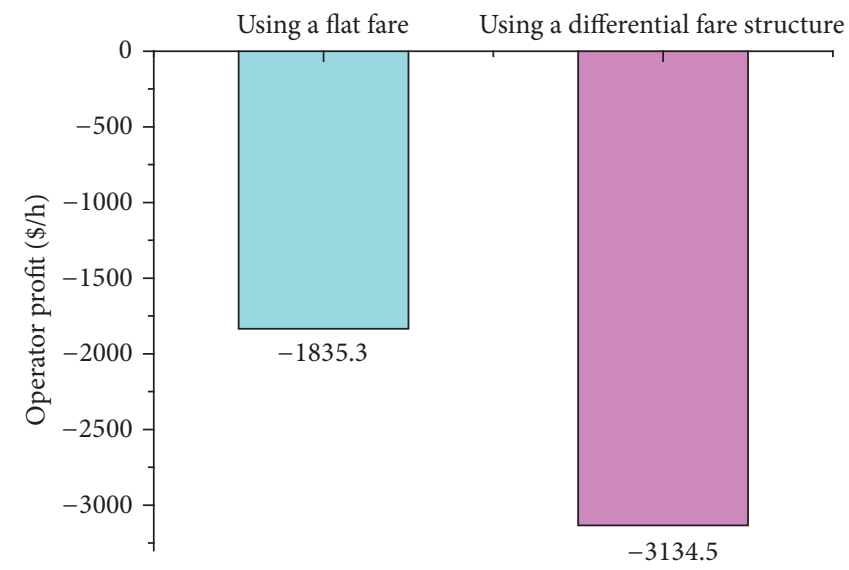

(e) Operator profits $(\$ / h)$

FIGURE 6: Optimal results of two models using flat and differential fare structures.

of consumer surplus of about $\$ 1626.0 / \mathrm{h}$, increased attraction of passengers by approximately 208 passengers, and, in particular, saving of an average fare per passenger by about $\$ 0.287$, as shown in Figures $6(\mathrm{a})-6(\mathrm{~d})$. It illustrates that using a differential fare structure in optimizing operational strategies shows more profitable, to a degree of considerable significance compared to using a flat fare.

3.3. Sensitivity Analysis for a Differential Fare Structure. In this study, a differential fare function is developed based on 
TABLE 5: Results of two objectives with and without optimal strategies based on a differential fare table.

\begin{tabular}{|c|c|c|c|c|c|c|c|c|c|}
\hline & Type & $\begin{array}{c}\text { Frequency } \\
\text { (buses/h) }\end{array}$ & $\begin{array}{l}\text { Round trip } \\
\text { time } \\
\text { (min) }\end{array}$ & $\begin{array}{c}\text { Demand } \\
\text { (passengers/h) }\end{array}$ & $\begin{array}{l}\text { Unit fare } \\
(\$ / \mathrm{km})\end{array}$ & $\begin{array}{c}\text { Fleet size } \\
\text { (buses) }\end{array}$ & $\begin{array}{c}\text { Operator } \\
\text { profit } \\
(\$ / \mathrm{h})\end{array}$ & $\begin{array}{c}\text { Consumer } \\
\text { surplus } \\
(\$ / \mathrm{h})\end{array}$ & $\begin{array}{c}\text { Objective } \\
\text { function } \\
\text { value } \\
(\$ / \mathrm{h})\end{array}$ \\
\hline \multirow{2}{*}{$\begin{array}{l}\text { Optimal } \\
\text { strategies }\end{array}$} & FRO & 13.0 & 137.4 & \multirow{2}{*}{6439} & \multirow{2}{*}{0.50} & \multirow{2}{*}{60} & \multirow{2}{*}{-3134.5} & \multirow{2}{*}{23957.6} & \multirow{2}{*}{20823.1} \\
\hline & Limited stop & 14.8 & 122.8 & & & & & & \\
\hline \multirow[t]{2}{*}{$\begin{array}{l}\text { Without } \\
\text { strategies }\end{array}$} & FRO & 24.1 & 137.4 & 6315 & 0.51 & 55 & -3010.9 & 23185.8 & 20174.9 \\
\hline & & & & 124 & -0.01 & 5 & -123.6 & 771.8 & 648.2 \\
\hline
\end{tabular}

trip distance and obtained service levels. This section will discuss the degree of how much passengers are willing to pay for service levels provided. Weight factor of fare per unit distance for each pair calculated by (7) is used to show their obtained service levels. A parameter $\varepsilon$ is added in (7) as follows:

$$
\pi_{l}^{i j}=1+\varepsilon \frac{N_{l, \text { skip }}^{i j}}{N^{i j}} .
$$

The second part on the right hand side of (27) represents the proportion of additional service fee in fare per unit distance that passengers from pair $(i, j)$ on strategy $l$ are willing to pay for gaining high service levels. Passengers do not need to pay an additional fee for high quality of service, if $\varepsilon$ equals zero. The greater the value of $\varepsilon$ is, the greater the proportion of additional service fee in fare per unit distance is. Note that the differential fare structure based on trip distance and obtained service levels will be based on travel distances if the value of the second part equals zero.

Figure 7 shows that optimal results change as the value of parameter $\varepsilon$ related to additional service fee increases, in terms of objective function value, operator profit, consumer surplus, demand, and fare per unit distance. As shown in Figure 7(a), it is found that the greatest objective function value is about $\$ 20949.0 / \mathrm{h}$ when the value of $\varepsilon$ equals 0. It gradually decreases with the value of $\varepsilon$ increasing from 0 to 250. It is invariant when the value of $\varepsilon$ is greater than 250 . That is, as is shown by (27), the weight factor of fare per unit distance for each pair must increase with the increase of the value of parameter $\varepsilon$, thus reducing passenger demand and the objective function value; this is given the use of the limited stop strategy to serve the same set of stops using the service frequency. According to Figure 7(f), it is found that the frequency of the limited stop strategy decreases gradually while the frequency of the FRO strategy increases with the increase of the value of parameter $\varepsilon$ from 0 to 250. This aims to reduce the adverse effects on the objective function value generated by increased weight factor of fare per unit distance. When the value of parameter $\varepsilon$ increases to be greater than 250 , the limited stop strategy makes a maximum adverse contribution to the objective function value which is less than that from the model using the FRO strategy. Therefore, the skipped strategy is abandoned, except the FRO strategy. By using only the FRO strategy, the value of weight factor of fare per unit distance equals 1 regardless of the increase of parameter $\varepsilon$, because of the second term of (27) being zero. That is, the differential fare is constructed only based on trip distances. The objective function value becomes a fixed constant in a FRO strategy problem. Accordingly, this also explains why other components of optimal results, as shown in Figures $7(\mathrm{~b})-7(\mathrm{e})$, are constant when the value of $\varepsilon$ is greater than 250. In addition, the value of objective function using this differential fare structure is less than that by about $\$ 20496.3 / \mathrm{h}$ using a flat fare, when the value of $\varepsilon$ is greater than 10 . This indicates a flat fare is more profitable than a differential fare for the application of strategies, if the additional service fee is high and more than a threshold.

It is obvious that the effect of an additional service fee on a trip fare will become greater, as the value of $\varepsilon$ rises from 0 to 250, according to (27). In order to lower the increasing adverse effects, of an additional service fee on the value of the objective function, the optimization model also attempts to reduce the optimal fare per unit distance to the extent possible in Figure 7(e); this is except for the method, mentioned above, that reduces frequency of the limited stop strategy and increases frequency of the FRO strategy in Figure 7(f). In Figure 7(b) the operator profit increases to a fixed constant as the value of $\varepsilon$ increases. The demand and consumer surplus present an opposite trend (see Figures 7(c) and 7(d)) to that of operator profit. It is found that there is a drastic change of the operator profit, consumer surplus, demand, and fare per unit distance once the value of $\varepsilon$ increases from 200 to 250 . This is directly related to the use of operational strategies. For $\varepsilon$ close to 250 , the use of the combined limited stop and FRO strategies is transformed into only using the FRO strategy in Figure 7(f). In the former case, the value of $\varepsilon$ has a great adverse effect on the objective function value, while there is no effect in the latter. Additionally, consumer surplus achieves the maximum value when the value of $\varepsilon$ equals zero, while the operator profit is at its minimum level. This offers transport planners and decision makers a way to make a beneficial service from the perspectives of the society, passengers, and operators. Multiple operational strategies integrated with a distance based fare structure can bring the maximum benefits for the society and passengers, with a minimum profit for operators. The multiple operational strategies integrated with a distance based and service based fare structure can present a better tradeoff between passengers and operators. If decision makers want to obtain the maximum profit for operators, FRO strategies with a distance based fare structure ought to be used. 


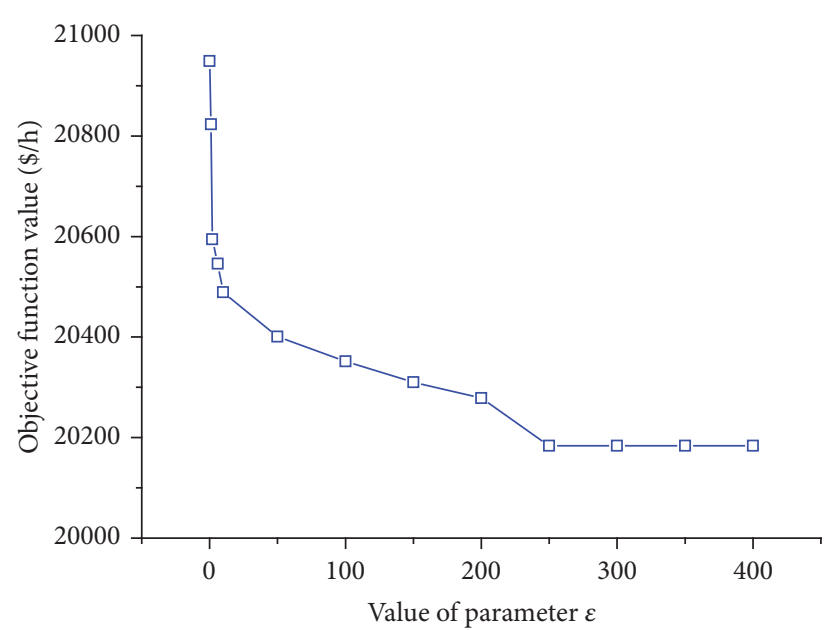

$-\square-$ Objective function value

(a) Objective function value $(\$ / \mathrm{h})$

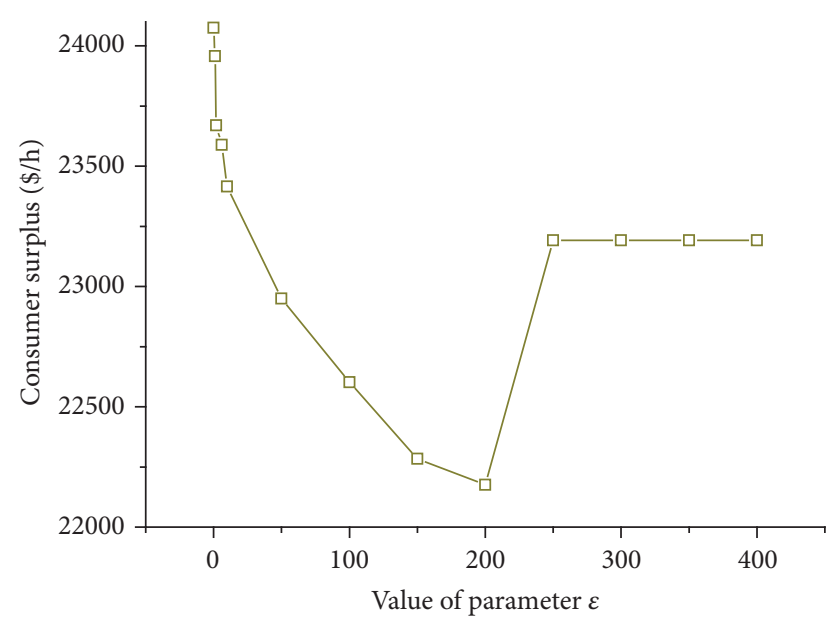

$-\square-$ Consumer surplus

(c) Consumer surplus $(\$ / \mathrm{h})$

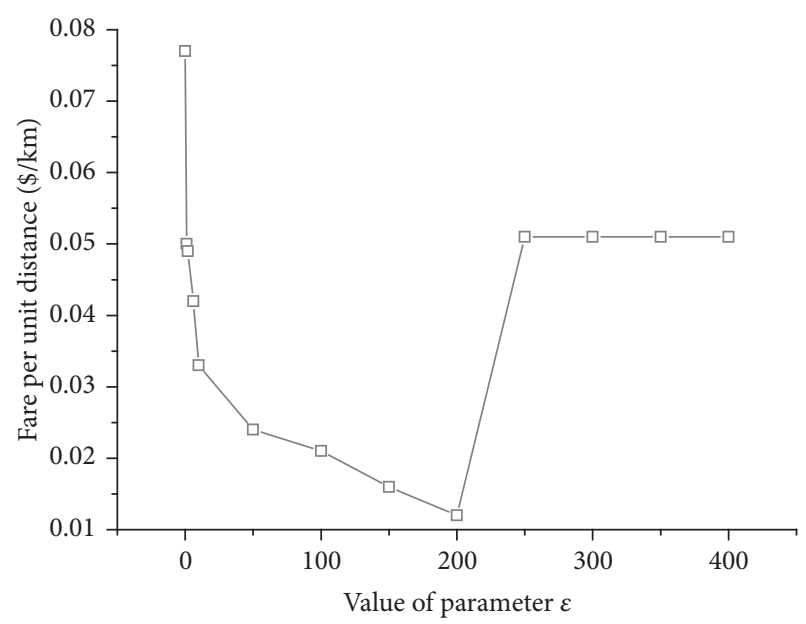

$-\square-$ Fare per unit distance

(e) Fare per unit distance $\operatorname{pr}(\$ / \mathrm{km})$

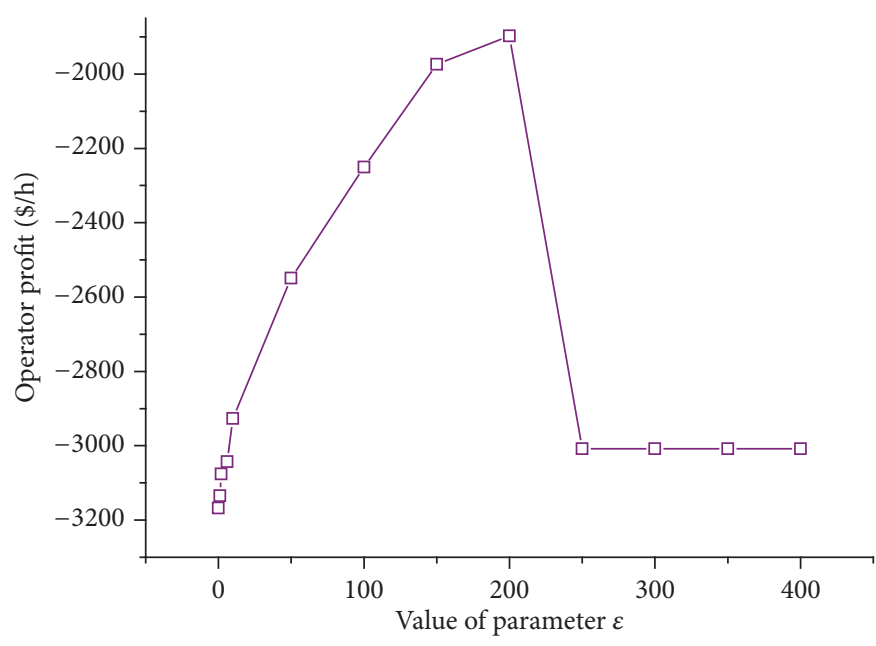

$-\square-$ Operator profit

(b) Operator profit $(\$ / \mathrm{h})$

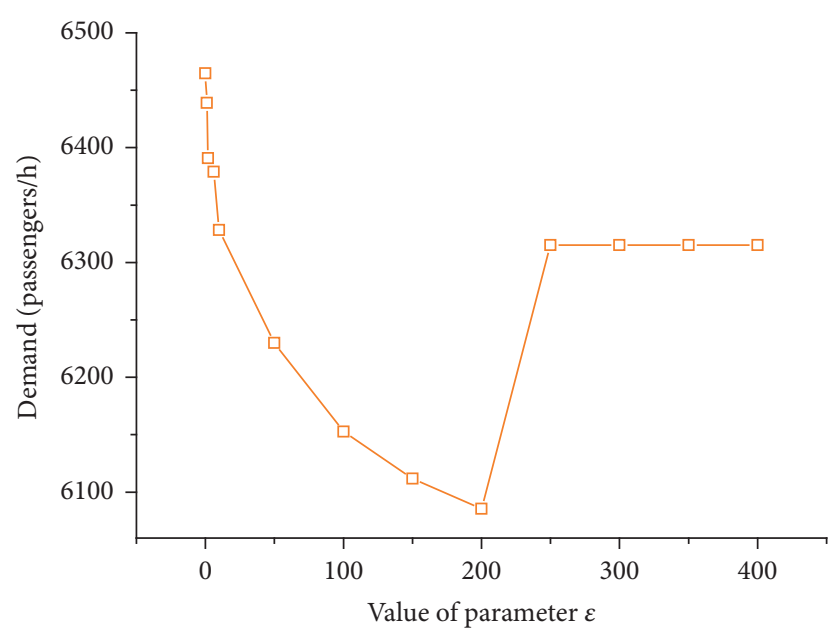

- - Demand

(d) Demand (passengers/h)

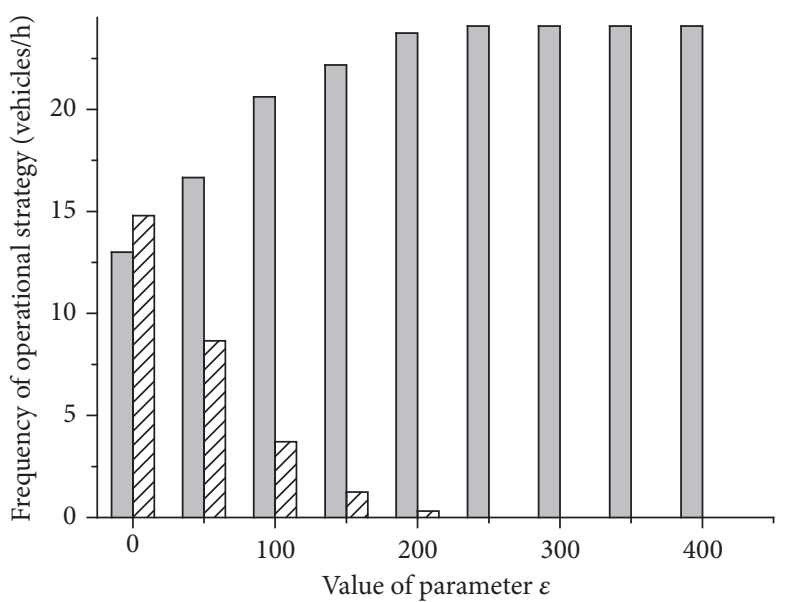

FRO

Limited stop

(f) Frequency of operational strategy (vehicles/h)

FIGURE 7: The effects of parameter $\varepsilon$ related to additional service fee on optimal results. 


\section{Conclusion}

This work focuses on operational strategies and fare problems on a bus line. These operational strategies consist of FRO, limited stop, short turn, and mixed strategies, constructed on the basis of passenger demand. According to characteristics of this transit operation system, a fare table is proposed. This fare table can be presented for a flat fare and a differential fare structure, depending on fare policy objectives. Both types of fare structure are considered in this study, in order to seek a more suitable, profitable fare structure for the application of strategies. The differential fare structure proposed is constructed on the basis of trip distance and obtained service levels. Moreover, passenger demand is sensitive with respect to waiting time, in-vehicle time, fare, and crowding time in vehicles. This allows for investigating the effects of using operational strategies and two types of fare structures on passengers and the operators, as well as the transit system as a whole. The strategies and fare problems, therefore, are formulated as optimization models, with the objective of maximizing a sum of benefits of users and operators.

This model has been applied to a real life example in Dalian, China. It shows that using strategies can improve results by gains of $\$ 648.2 / \mathrm{h}$ for objective function value and consumer surplus gains of $\$ 771.8 / \mathrm{h}$ and attracting more than 124 passengers, despite a small loss in operating profit of $\$ 123.6 / \mathrm{h}$, compared with applying FRO strategy exclusively, when a differential fare structure is applied for both optimization models. Clearly, passenger gains can compensate for this loss of operator profit.

In addition, in comparison with optimizing strategies considering a flat fare, a differential structure proves more profitable in terms of objective function value, passenger surplus, and demand, if the value of parameter $\varepsilon$ related to additional service fee is less than 10 . This illustrates that using optimal operational strategies integrated with a differential fare structure can further improve a transit operation system.

Moreover, sensitivity analysis is conducted to examine the effect of an additional service fee on optimal results. It is found that operational strategies using a flat fare provide greater objective function value than those using a differential fare, when the value of parameter $\varepsilon$ related to additional service fee is between 10 and 250 . Interestingly, when this value increases to the point of exceeding 250, skipped strategy, except for FRO, may be abandoned due to a high additional service fee required for providing high service levels. This indicates that FRO strategy performs in a more beneficial manner when the proportion of the additional service fee for a trip fare is more than a threshold.

Future research could extend the proposed methodology to include provision of information on bus arrival/departure and running, passengers transferring between vehicle trips associated with different operational strategies, and transport emissions considerations. In the modern, multimodel, urban transportation system, the application of an optimal combination of operational strategies integrated into a differential fare structure, may drive more travelers to leave their cars and turn to public transit services in deference to resulting high service levels of the transit service. The online information can be provided via smartphone and Internet and thus allows for reducing waiting time by timing arrival at stops. We also note that some passengers may transfer between vehicle trips associated with different operational strategies when transferring costs are less than their obtained travel savings. Moreover, operational strategies' attributes can reduce transit emissions by reducing the number of "stops and goes," though this is not explicitly discussed in this study. This would be inserted into the objective function.

\section{Notations}

$A_{\text {max }}: \quad$ The maximum number of passengers inside a vehicle with an accepted comfortable level (passengers/vehicle)

$\mathrm{AT}_{p}^{l}$ : $\quad$ Passenger alighting times for a bus using

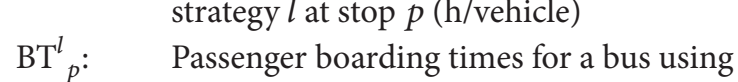
strategy $l$ at stop $p$ (h/vehicle)

$\mathrm{CO}_{\text {operator }}$ : Operating cost per bus hour (\$/vehicle h)

$\mathrm{CR}^{i j}: \quad$ Average crowding time for pair $(i, j)(\mathrm{h})$

$\mathrm{CS}_{\text {user }}$ : Consumer surplus for trips $(\$ / \mathrm{h})$

$C_{\text {operator: }}$ Operator cost $(\$ / \mathrm{h})$

$\mathrm{DT}^{i j}{ }_{l}$ : $\quad$ Dwell time of a bus using strategy $l$ between stop $i$ and stop $j$ (h/vehicle)

$d^{i j}: \quad \quad \quad \quad$ Trip distance for pair $(i, j)(\mathrm{km})$

$E$ : $\quad$ Set of end stop of strategies

$e_{\mathrm{TW}}$ : Demand elasticity parameter for waiting time

$e_{\mathrm{TV}}$ : Demand elasticity parameter for in-vehicle time

$e_{\mathrm{FA}}$ : Demand elasticity parameter for fare

$e_{\mathrm{CR}}$ : Demand elasticity parameter for crowding time

$\mathrm{FA}^{i j}: \quad$ Bus fare for pair $(i, j)(\$)$

$f_{l}: \quad$ Frequency of strategy $l$ (vehicles $\left./ \mathrm{h}\right)$

$G_{\text {operator }}: \quad$ Operator revenues $(\$ / \mathrm{h})$

$g_{i j}$ : $\quad$ Potential demand for pair $(i, j)$ along a bus line (passengers/h)

$K T_{l}$ : $\quad$ Layover time of strategy $l$ on a bus line at the turning point $(\mathrm{h})$

L: $\quad$ A set of bus strategies serving a bus line, including full route operation (FRO), short turn (ST), limited stop (LS), and a mix of limited stop and short turn (MLS)

$N$ : $\quad$ Set of stops on a bus line

$N_{l}: \quad$ Set of feasible stops on strategy $l$

$N^{i j}{ }_{l \text { skip }}$ : The skipped number of stops that a bus using strategy $l$ travels from stop $i$ to stop $j$

$N^{i j}$ : The number of stops from stop $i$ to stop $j$ on a bus route

$\mathrm{OP}_{\text {operator }}$ : Operator profit $(\$ / \mathrm{h})$

pr: $\quad$ Fare per unit distance $(\$ / \mathrm{km})$

Q: $\quad$ Capacity of vehicle (passengers/vehicle)

$q$ : $\quad$ An demand variable of the inverse function of elastic demand function with the upper boundary $V_{i j}$

$\mathrm{RT}^{i j}{ }_{l}$ : $\quad$ Running time of a bus using strategy $l$ between stop $i$ and stop $j$ (h/vehicle)

$\mathrm{RT}_{l}$ : $\quad$ Running time of strategy $l$ on a bus line (h) 


\begin{tabular}{|c|c|}
\hline : & $\begin{array}{l}\text { unning time for a bus from stop } p \text { to stop } \\
+1 \text { (h/vehicle) }\end{array}$ \\
\hline & Set of start stop of strategies \\
\hline & erage in-vehicle time for pair $(i, j)(h)$ \\
\hline & aiting time for pair $(i, j)(\mathrm{h})$ \\
\hline & $\begin{array}{l}\text { Average boarding time per passenger } \\
\text { passenger) }\end{array}$ \\
\hline$:$ & $\begin{array}{l}\text { alighting time per passenger }(\mathrm{h} / \mathrm{t} \\
\mathrm{r} \text { ) }\end{array}$ \\
\hline J: & all $O-D$ pairs $(\$)$ \\
\hline$i_{i j}:$ & ber of passengers for pair \\
\hline l. & $\begin{array}{l}\text { f onboard passengers for a } \\
\text { gy } l \text { departing from stop } p \\
\text { iicle) }\end{array}$ \\
\hline$-1 \quad(a)$ & on of elastic demand \\
\hline${ }^{i j}:$ & $\begin{array}{l}\text { Crowding time for pair }(i, j) \text { using strategy } \\
l(\mathrm{~h})\end{array}$ \\
\hline Z: & $\begin{array}{l}\text { sum of consumer surplus and operator } \\
\text { it }(\$ / \mathrm{h})\end{array}$ \\
\hline$\eta_{p}^{i j}:$ & $\begin{array}{l}\text { Equals } 1 \text { if } \mathrm{p} \\
\text { boarding at st }\end{array}$ \\
\hline$p_{p}^{i j}:$ & $\begin{array}{l}\text { gers of pair }(i, j) \text { are } \\
\text { nd } 0 \text { otherwise }\end{array}$ \\
\hline$\Phi_{p}^{i j}:$ & $\begin{array}{l}\text { Equals } 1 \text { if passengers of pair }(i, j) \text { are } \\
\text { passing through stop } p \text { and } 0 \text { otherwise }\end{array}$ \\
\hline & $\begin{array}{l}\text { sting of deceleration/ } \\
\text { as doors opening and } \\
\text { stop (h/vehicle) }\end{array}$ \\
\hline & $\begin{array}{l}\text { A parameter depending on the distribution } \\
\text { of bus arrivals at each stop; when bus arrival } \\
\text { is Poisson-distributed, } \lambda \text { will be equal to } 1\end{array}$ \\
\hline & $\begin{array}{l}\text { used to adjust the proportion } \\
\text { dditional service fee in fare per }\end{array}$ \\
\hline${ }^{i j}{ }_{l}^{i j}:$ & $\begin{array}{l}\text { Weight factor of unit fare for pair }(i, j) \text { using } \\
\text { strategy } l \text {, depending on pair }(i, j) \text { obtained } \\
\text { service levels }\end{array}$ \\
\hline & Binary variable; taking the va \\
\hline
\end{tabular}

\section{Conflicts of Interest}

The authors declare that they have no conflicts of interest.

\section{Acknowledgments}

The first author would like to acknowledge the support of the China Scholarship Council (CSC) for this study.

\section{References}

[1] A. Ceder, Public Transit Planning and Operation: Theory, Modeling and Practice, Elsevier, Oxford, UK, 2007.

[2] A. Ceder, Public Transit Planning and Operation: Modeling. Practice and Behavior, CRC Press, Boca Raton, Fla, USA, 2nd edition, 2016.
[3] P. G. Furth and F. B. Day, "Transit routing and scheduling strategies for heavy demand corridors," Transportation Research Record, vol. 1101, pp. 23-26, 1985.

[4] P. G. Furth, "Short turning on transit routes," Transportation Research Record, vol. 1108, pp. 42-52, 1987.

[5] A. Ceder, "Optimal design of transit short-turn trips," Transportation Research Record, vol. 1221, pp. 8-22, 1989.

[6] P. Delle Site and F. Filippi, "Service optimization for bus corridors with short-turn strategies and variable vehicle size," Transportation Research Part A: Policy and Practice, vol. 32, no. 1, pp. 19-38, 1998.

[7] A. Tirachini, C. E. Cortés, and S. R. Jara-Díaz, "Optimal design and benefits of a short turning strategy for a bus corridor," Transportation, vol. 38, no. 1, pp. 169-189, 2011.

[8] C. E. Cortés, S. Jara-Díaz, and A. Tirachini, "Integrating short turning and deadheading in the optimization of transit services," Transportation Research Part A: Policy and Practice, vol. 45, no. 5, pp. 419-434, 2011.

[9] L. Fu, Q. Liu, and P. Calamai, "Real-time optimization model for dynamic scheduling of transit operations," Transportation Research Record, no. 1857, pp. 48-55, 2003.

[10] Z. Liu, Y. Yan, X. Qu, and Y. Zhang, "Bus stop-skipping scheme with random travel time," Transportation Research Part C: Emerging Technologies, vol. 35, pp. 46-56, 2013.

[11] J. Chen, Z. Liu, S. Zhu, and W. Wang, "Design of limited-stop bus service with capacity constraint and stochastic travel time," Transportation Research Part E: Logistics and Transportation Review, vol. 83, pp. 1-15, 2015.

[12] C. Leiva, J. C. Muñoz, R. Giesen, and H. Larrain, "Design of limited-stop services for an urban bus corridor with capacity constraints," Transportation Research Part B: Methodological, vol. 44, no. 10, pp. 1186-1201, 2010.

[13] P. R. Tétreault and A. M. El-Geneidy, "Estimating bus run times for new limited-stop service using archived AVL and APC data," Transportation Research Part A: Policy and Practice, vol. 44, no. 6, pp. 390-402, 2010.

[14] A. M. El-Geneidy and J. Surprenant-Legault, "Limited-stop bus service: an evaluation of an implementation strategy," Public Transport, vol. 2, no. 4, pp. 291-306, 2010.

[15] V. Chiraphadhanakul and C. Barnhart, "Incremental bus service design: combining limited-stop and local bus services," Public Transport, vol. 5, no. 1-2, pp. 53-78, 2013.

[16] Y. Y. Ulusoy, S. Chien, and C.-H. Wei, "Optimal all-stop, short-turn, and express transit services under heterogeneous demand," Transportation Research Record, no. 2197, pp. 8-18, 2010.

[17] Y. Y. Ulusoy and S. I.-J. Chien, “Optimal bus service patterns and frequencies considering transfer demand elasticity with genetic algorithm," Transportation Planning and Technology, vol. 38, no. 4, pp. 409-424, 2015.

[18] A. Evans, "A theoretical comparison of competition with other economic regimes for bus services," Journal of Transport Economics \& Policy, vol. 21, no. 1, pp. 7-36, 1987.

[19] H. Yang and H.-J. Huang, "Analysis of the time-varying pricing of a bottleneck with elastic demand using optimal control theory," Transportation Research Part B: Methodological, vol. 31, no. 6, pp. 425-440, 1997.

[20] W. H. K. Lam and J. Zhou, "Optimal fare structure for transit networks with elastic demand," Transportation Research Record, no. 1733 , pp. $8-14,2000$. 
[21] H. Yang and W. K. Kin, "Modeling bus service under competition and regulation," Journal of Transportation Engineering, vol. 126, no. 5, pp. 419-425, 2000.

[22] G. Bellei, G. Gentile, and N. Papola, "Network pricing optimization in multi-user and multimodal context with elastic demand," Transportation Research Part B: Methodological, vol. 36, no. 9, pp. 779-798, 2002.

[23] J.-L. Yao, C.-F. Hou, Z.-X. Yang, and C. Fu, "Optimization study on road pricing with variable bus frequency," Journal of Transportation Systems Engineering and Information Technology, vol. 10, no. 2, pp. 93-99, 2010.

[24] F. Jørgensen, T. A. Mathisen, and B. Larsen, "Evaluating transport user benefits and social surplus in a transport market- the case of the Norwegian ferries," Transport Policy, vol. 18, no. 1, pp. 76-84, 2011.

[25] M. J. Klier and K. Haase, "Urban public transit network optimization with flexible demand," OR Spectrum. Quantitative Approaches in Management, vol. 37, no. 1, pp. 195-215, 2015.

[26] S. K. Chang and P. M. Schonfeld, "Multiple period optimization of bus transit systems," Transportation Research Part B, vol. 25, no. 6, pp. 453-478, 1991.

[27] S. I.-J. Chien and L. N. Spasovic, "Optimization of grid bus transit systems with elastic demand," Journal of Advanced Transportation, vol. 36, no. 1, pp. 63-91, 2002.

[28] F.-M. Tsai, S. I.-J. Chien, and L. N. Spasovic, “Optimizing distance-based fares and headway of an intercity transportation system with elastic demand and trip length differentiation," Transportation Research Record, no. 2089, pp. 101-109, 2008.

[29] I. Savage, "The dynamics of fare and frequency choice in urban transit," Transportation Research Part A: Policy and Practice, vol. 44, no. 10, pp. 815-829, 2010.

[30] Z.-C. Li, W. H. K. Lam, S. C. Wong, and A. Sumalee, "Design of a rail transit line for profit maximization in a linear transportation corridor," Transportation Research Part E: Logistics and Transportation Review, vol. 48, no. 1, pp. 50-70, 2012.

[31] M. E. Kim and P. Schonfeld, "Maximizing net benefits for conventional and flexible bus services," Transportation Research Part A: Policy and Practice, vol. 80, pp. 116-133, 2015.

[32] R. Voith, "Fares, service levels, and demographics: what determines commuter rail ridership in the long run?" Journal of Urban Economics, vol. 41, no. 2, pp. 176-197, 1997.

[33] R. A. Petitte, "Fare variable construction and rail transit ridership elasticities case study of the Washington, D.C., metrorail system," Transportation Research Record, no. 1753, pp. 102-110, 2001.

[34] N. Paulley, R. Balcombe, R. Mackett et al., "The demand for public transport: the effects of fares, quality of service, income and car ownership," Transport Policy, vol. 13, no. 4, pp. 295-306, 2006.

[35] O. Cats, J. West, and J. Eliasson, "A dynamic stochastic model for evaluating congestion and crowding effects in transit systems," Transportation Research Part B: Methodological, vol. 89, pp. 4357, 2016.

[36] D. Fleishman, N. Shaw, M. Joshi, and R. Freeze, "Fare policies, structures, and technologies," TCRP Report 10, Transportation Research Board, Washington, DC, USA, 1996.

[37] S. I.-J. Y. Chien and C. F. M. Tsai, “Optimization of fare structure and service frequency for maximum profitability of transit systems," Transportation Planning and Technology, vol. 30, no. 5, pp. 477-500, 2007.
[38] Z.-C. Li, W. H. Lam, and S. C. Wong, "The optimal transit fare structure under different market regimes with uncertainty in the network," Networks and Spatial Economics, vol. 9, no. 2, pp. 191-216, 2009.

[39] K. Gkritza, M. G. Karlaftis, and F. L. Mannering, "Estimating multimodal transit ridership with a varying fare structure," Transportation Research Part A: Policy and Practice, vol. 45, no. 2, pp. 148-160, 2011.

[40] F.-M. Tsai, S. Chien, and C.-H. Wei, "Joint optimization of temporal headway and differential fare for transit systems considering heterogeneous demand elasticity," Journal of Transportation Engineering, vol. 139, no. 1, pp. 30-39, 2013.

[41] D. Yook and K. Heaslip, "Determining appropriate fare levels for distance-based fare structure: considering users' behaviors in a time-expanded network," Transportation Research Record, vol. 2415, pp. 127-135, 2014.

[42] Z. Li and D. A. Hensher, "Crowding and public transport: a review of willingness to pay evidence and its relevance in project appraisal," Transport Policy, vol. 18, no. 6, pp. 880-887, 2011.

[43] G. Kocur and C. Hendrickson, "Design of local bus service with demand equilibration," Transportation Science, vol. 16, no. 2, pp. 149-170, 1982.

[44] J. Viswanathan and I. E. Grossmann, "A combined penalty function and outer-approximation method for MINLP optimization," Computers and Chemical Engineering, vol. 14, no. 7, pp. 769-782, 1990.

[45] A. Brooke, D. Kendrick, A. Meeraus, and R. Raman, GAMS: A User's Guide, GAMS Development Corporation, Washington, DC, USA, 2005.

[46] I. E. Grossmann, J. Viswanathan, and A. Vecchiette, DICOPT User's Manual, GAMS Development Corporation, Washington, DC, USA, 2008.

[47] Transportation Research Board, Transit Capacity and Quality of Service Manual, Transit Cooperative Research Program, Report 100, Transportation Research Board, Washington, DC, USA, 2nd edition, 2003. 


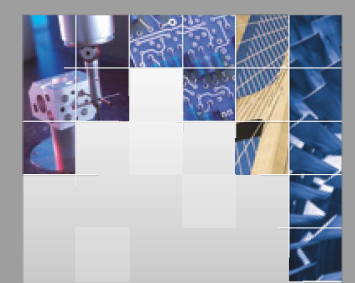

\section{Enfincering}
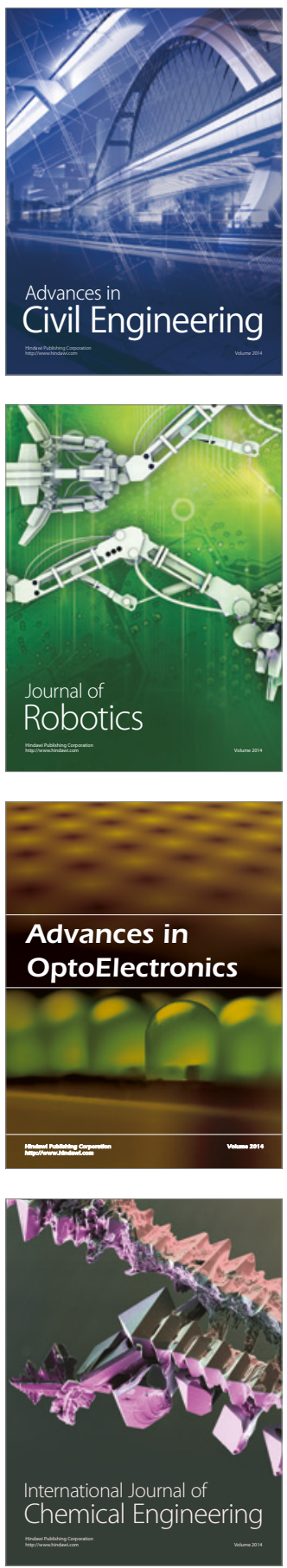

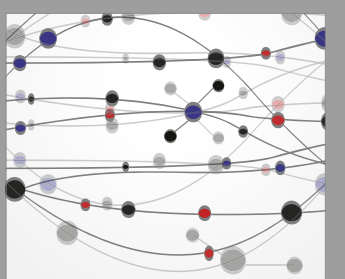

The Scientific World Journal

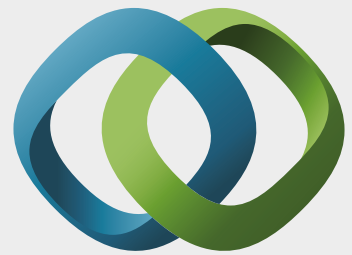

\section{Hindawi}

Submit your manuscripts at

https://www.hindawi.com
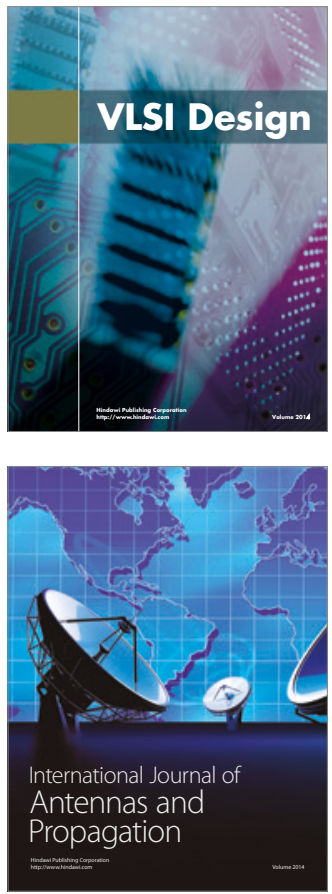

\section{Rotating}

Machinery
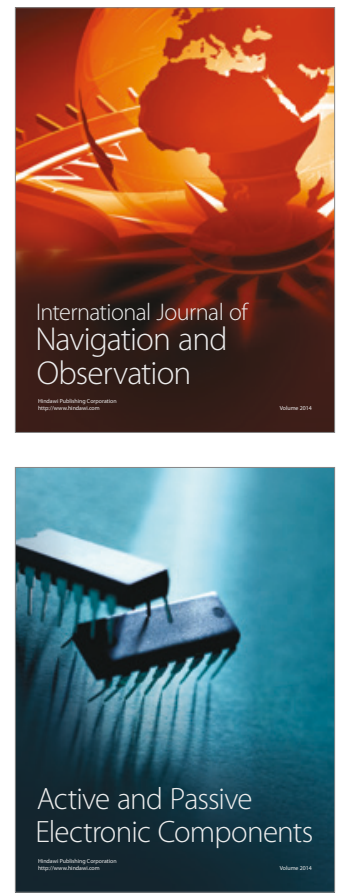
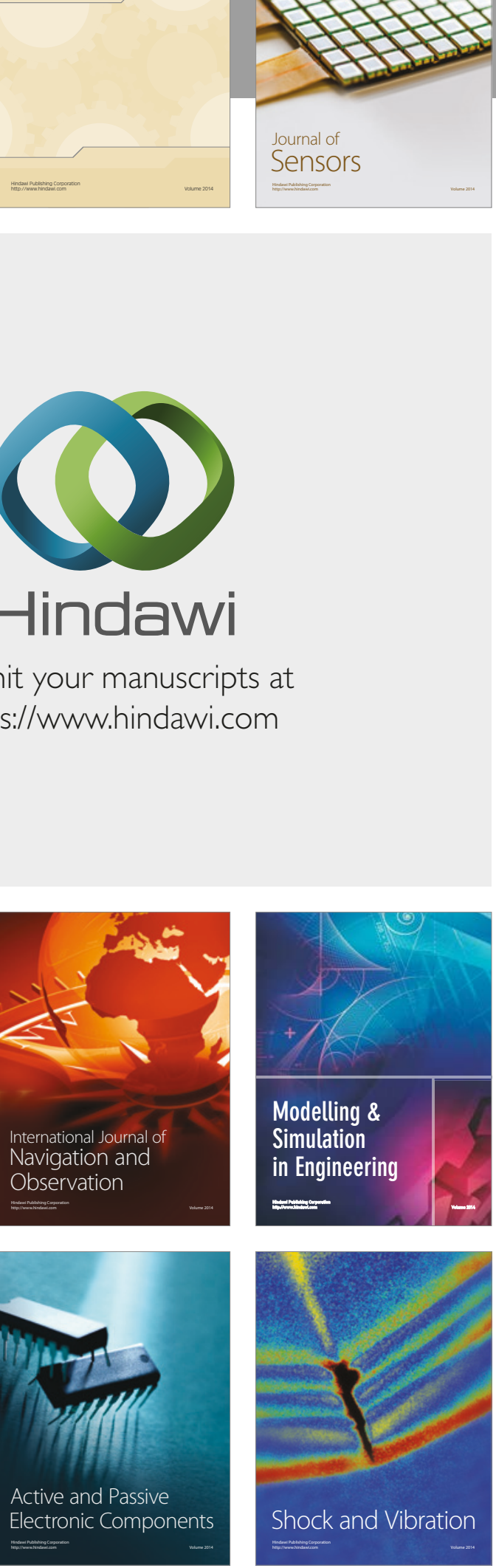
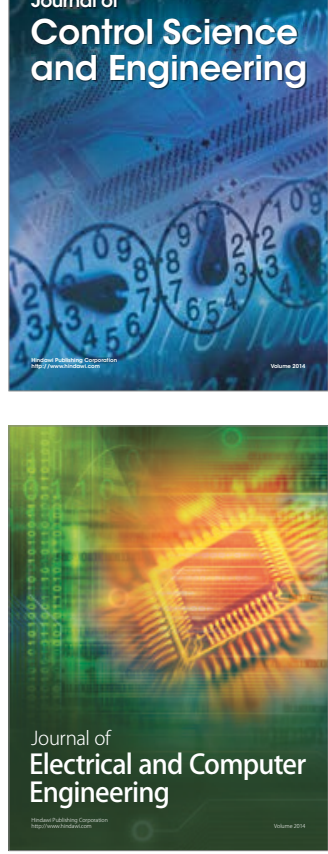

Distributed

Journal of

Control Science

and Engineering
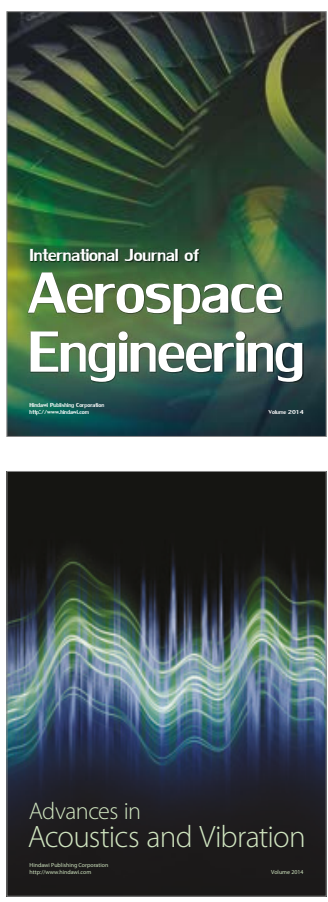

Sensor Networks 